Atmos. Chem. Phys., 19, 13681-13699, 2019

https://doi.org/10.5194/acp-19-13681-2019

(C) Author(s) 2019. This work is distributed under

the Creative Commons Attribution 4.0 License.
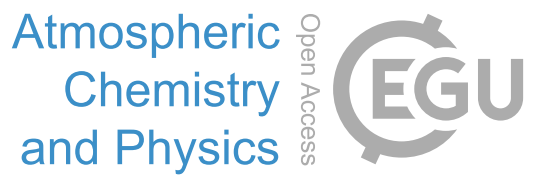

\title{
Nitrification of the lowermost stratosphere during the exceptionally cold Arctic winter 2015-2016
}

\author{
Marleen Braun $^{1}$, Jens-Uwe Grooß ${ }^{2}$, Wolfgang Woiwode ${ }^{1}$, Sören Johansson ${ }^{1}$, Michael Höpfner ${ }^{1}$, Felix Friedl-Vallon ${ }^{1}$, \\ Hermann Oelhaf $^{1}$, Peter Preusse ${ }^{2}$, Jörn Ungermann ${ }^{2}$, Björn-Martin Sinnhuber ${ }^{1}$, Helmut Ziereis ${ }^{3}$, and \\ Peter Braesicke ${ }^{1}$ \\ ${ }^{1}$ Institute of Meteorology and Climate Research, Karlsruhe Institute of Technology, Karlsruhe, Germany \\ ${ }^{2}$ Institute of Energy and Climate Research, Stratosphere (IEK-7), Forschungszentrum Jülich, Jülich, Germany \\ ${ }^{3}$ Institute of Atmospheric Physics, German Aerospace Center, Oberpfaffenhofen, Germany
}

Correspondence: Marleen Braun (marleen.braun@kit.edu)

Received: 1 February 2019 - Discussion started: 4 March 2019

Revised: 2 September 2019 - Accepted: 5 October 2019 - Published: 11 November 2019

\begin{abstract}
The Arctic winter 2015-2016 was characterized by exceptionally low stratospheric temperatures, favouring the formation of polar stratospheric clouds (PSCs) from midDecember until the end of February down to low stratospheric altitudes. Observations by GLORIA (Gimballed Limb Observer for Radiance Imaging of the Atmosphere) on HALO (High Altitude and LOng range research aircraft) during the PGS (POLSTRACC-GW-LCYCLE II-SALSA) campaign from December 2015 to March 2016 allow the investigation of the influence of denitrification on the lowermost stratosphere (LMS) with a high spatial resolution. Twodimensional vertical cross sections of nitric acid $\left(\mathrm{HNO}_{3}\right)$ along the flight track and tracer-tracer correlations derived from the GLORIA observations document detailed pictures of wide-spread nitrification of the Arctic LMS during the course of an entire winter. GLORIA observations show largescale structures and local fine structures with enhanced absolute $\mathrm{HNO}_{3}$ volume mixing ratios reaching up to $11 \mathrm{ppbv}$ at altitudes of $13 \mathrm{~km}$ in January and nitrified filaments persisting until the middle of March. Narrow coherent structures tilted with altitude of enhanced $\mathrm{HNO}_{3}$, observed in mid-January, are interpreted as regions recently nitrified by sublimating $\mathrm{HNO}_{3}$-containing particles. Overall, extensive nitrification of the LMS between 5.0 and $7.0 \mathrm{ppbv}$ at potential temperature levels between 350 and $380 \mathrm{~K}$ is estimated. The GLORIA observations are compared with CLaMS (Chemical Lagrangian Model of the Stratosphere) simulations. The fundamental structures observed by GLORIA are well reproduced, but differences in the fine structures are diagnosed. Further,
\end{abstract}

CLaMS predominantly underestimates the spatial extent of $\mathrm{HNO}_{3}$ maxima derived from the GLORIA observations as well as the overall nitrification of the LMS. Sensitivity simulations with CLaMS including (i) enhanced sedimentation rates in case of ice supersaturation (to resemble ice nucleation on nitric acid trihydrate (NAT)), (ii) a global temperature offset, (iii) modified growth rates (to resemble aspherical particles with larger surfaces) and (iv) temperature fluctuations (to resemble the impact of small-scale mountain waves) slightly improved the agreement with the GLORIA observations of individual flights. However, no parameter could be isolated which resulted in a general improvement for all flights. Still, the sensitivity simulations suggest that details of particle microphysics play a significant role for simulated LMS nitrification in January, while air subsidence, transport and mixing become increasingly important for the simulated $\mathrm{HNO}_{3}$ distributions towards the end of the winter.

\section{Introduction}

The processes of denitrification and nitrification are wellknown phenomena occurring in the polar winter stratosphere (Fahey et al., 1990). They involve the condensation, growth, sedimentation and sublimation of nitric acid $\left(\mathrm{HNO}_{3}\right)$-containing polar stratospheric cloud (PSC) particles and result in an irreversible vertical redistribution of $\mathrm{HNO}_{3}$. Denitrification is known to affect polar winter ozone loss ( $\mathrm{Fa}-$ hey et al., 1990; Waibel, 1999). Denitrification at higher lay- 
ers (i.e. around 16 to $22 \mathrm{~km}$ ) attenuates fast deactivation of catalytically active chlorine species into the reservoir species chlorine nitrate $\left(\mathrm{ClONO}_{2}\right)$. However, chlorine deactivation can be fostered at lower layers enriched in $\mathrm{HNO}_{3}$ (i.e. nitrified) by evaporating nitric acid trihydrate (NAT) particles (Fischer et al., 1997). Observational evidence for particles other than NAT involved in denitrification is sparse (e.g. Tabazadeh and Toon, 1996; Kim et al., 2006). Nitrification of the lowermost stratosphere is of particular interest since the chemical budget of reactive nitrogen $\left(\mathrm{NO}_{y}\right)$ and, thereby, its possible effects on ozone are modified in a region important for the radiative budget of the atmosphere (Riese et al., 2012).

While fundamental processes in connection with PSCs are well understood, there are still uncertainties concerning the formation of NAT particles and their characteristics that influence the processes of denitrification and nitrification. Chemistry-transport and global-chemistry models including simplified microphysical properties of NAT are generally successful in simulating denitrification of the polar winter stratosphere (Carslaw, 2002; Grooß et al., 2005, 2014; Khosrawi et al., 2017; Zhu et al., 2017, and references therein). However, parametrizations resulting in agreement with observed size distributions of NAT particles, particularly extremely large NAT particles, and reproducing fine structures of observed denitrification patterns remain an issue (e.g. Molleker et al., 2014; Woiwode et al., 2014).

Hemispheric differences in nitrification are observed due to different conditions in Antarctic and Arctic winter vortices. In the Antarctic, cold and stable vortices result in widespread PSC coverage and denitrification over wide vertical ranges. PSCs are observed less frequently in the Arctic, and the degree of denitrification varies from winter to winter (Santee et al., 1999; Pitts et al., 2018, and references therein). Increasing greenhouse gas emissions could lead to lower stratospheric temperatures (e.g. Rex et al., 2006), which likely cause stronger denitrification of the Arctic stratosphere.

Numerous studies addressed denitrification in Arctic winters, especially in cold winters, e.g. 1994-1995 (Waibel, 1999), 1999-2000 (Popp et al., 2001), 2004-2005 (Jin et al., 2006), 2009-2010 (Khosrawi et al., 2011; Woiwode et al., 2014), 2010-2011 (Sinnhuber et al., 2011) and 2015-2016 (Khosrawi et al., 2017). While most of these studies focused on the denitrification at altitudes higher than roughly $15 \mathrm{~km}$, less attention was paid to the associated nitrification of lower layers. Dibb et al. (2006) reported nitrification at potential temperature levels above $340 \mathrm{~K}$ (around $12 \mathrm{~km}$ ) at the end of January 2005. Further, Hübler et al. (1990) interpreted enhanced mixing ratios of up to $12 \mathrm{ppbv}$ at altitudes between 10 and $12.5 \mathrm{~km}$ in the Arctic winter 1988-1989 as resulting from nitrification. Tuck et al. (1997) found indications for nitrification in the Antarctic at levels above $400 \mathrm{~K}$ in the Antarctic winter 1994. Particularly, nitrification of the Arctic lowermost stratosphere (LMS) has hardly been investi- gated. This is due to the fact that cold winters with strong denitrification were rare events in the Arctic stratosphere in the past and that the observational capabilities to resolve nitrification of the LMS with sufficient coverage and vertical resolution are sparse. For example, limb sounders, like MLS (Microwave Limb Sounder; Waters et al., 2006) or MIPAS (Michelson Interferometer for Passive Atmospheric Sounding; Fischer et al., 2008) typically have vertical resolutions of around $3-5 \mathrm{~km}$ making it difficult to resolve fine-scale structures of $\mathrm{NO}_{y}$ redistribution.

The process of vertical $\mathrm{HNO}_{3}$ redistribution is very sensitive to temperature. NAT particle nucleation may begin as soon as temperatures fall below NAT equilibrium temperature $T_{\mathrm{NAT}}$. However, clear evidence of the precise nucleation conditions of NAT particles is still lacking. NAT particles are nucleated heterogeneously with low number densities on foreign nuclei such as meteoritic dust particles (Hoyle et al., 2013). Below $T_{\mathrm{NAT}}$, these particle grow and sediment downward, and they evaporate as temperatures rise above $T_{\mathrm{NAT}}$. A simulation of this process is challenging as it depends both on the nucleation parametrization and on the precise reproduction of the temperatures around $T_{\mathrm{NAT}}$. This is especially the case during the onset of this process. At a later time, to nucleate new NAT particles in denitrified air, lower temperatures are needed because of the already decreased $\mathrm{HNO}_{3}$ mixing ratios. This results in a maximum potential denitrification for a given temperature. Since both the nucleation process and the mesoscale temperature modulations (e.g. by gravity waves) are not well known, it is especially difficult to simulate the small-scale structure of $\mathrm{HNO}_{3}$ during the onset period.

Here, we present observations of nitrification of the LMS in the unusually cold Arctic winter 2015-2016 by the airborne limb-imaging Fourier transform infrared (FTIR) spectrometer GLORIA (Gimballed Limb Observer for Radiance Imaging of the Atmosphere, Friedl-Vallon et al., 2014; Riese et al., 2014). In that winter, an extraordinarily cold and stable polar vortex (Matthias et al., 2016; Manney and Lawrence, 2016) promoted a long-lasting PSC phase from mid-December until the end of February with a large vertical extent (Pitts et al., 2018; Voigt et al., 2018) reaching down into the LMS.

Using the GLORIA observations and simulations by the Chemical Lagrangian Model of the Stratosphere (CLaMS; Grooß et al., 2014, references therein), we investigate following research questions.

- How are $\mathrm{HNO}_{3}$ distributions structured in the LMS during the course of the cold Arctic winter 2015-2016? How do $\mathrm{HNO}_{3}$ distributions, which are affected by nitrification, compare with the stratospheric tracer ozone? How do observed small-scale spatial patters compare with a model (CLaMS)?

- Do tracer-tracer correlations constructed from GLORIA $\mathrm{HNO}_{3}$ and $\mathrm{O}_{3}$ indicate nitrification of the LMS? 
How does nitrification inferred from the GLORIA observations compare with that inferred from CLaMS? Can we identify a critical model parameter which results in a significant overall improvement of the agreement?

Thereby, we attempt to quantify the observed nitrification, which is particularly difficult because the LMS composition is influenced by air masses originating from the Arctic vortex, the extra-vortex stratosphere and the troposphere (Werner et al., 2010; Gettelman et al., 2011; Krause et al., 2018). $\mathrm{ClONO}_{2}$ also contributed significantly to lowermost stratospheric total $\mathrm{NO}_{y}$ during the Arctic winter 2015-2016. This aspect is addressed within a separate study by Johansson et al. (2019). Here we focus only on gas-phase $\mathrm{HNO}_{3}$, which is the direct product of nitrification by sublimating NAT particles.

We compare the GLORIA data with simulations by the CLaMS. To test how well different parametrizations within the same model reproduce the GLORIA observations, four sensitivity studies were performed. Those sensitivity simulations investigated the impact of (i) enhanced sedimentation rates in case of ice supersaturation, (ii) a global temperature offset, (iii) modified growth rates and (iv) temperature fluctuations.

\section{Aircraft campaign and data}

\subsection{POLSTRACC-GW-LCYCLE II-SALSA}

The GLORIA observations analysed in this study were obtained during the combined POLSTRACC (POLar STRAtosphere in a Changing Climate), GW-LCYCLE II (Gravity Wave Life Cycle Experiment) and SALSA (Seasonality of Air mass transport and origin in the Lowermost Stratosphere using the HALO Aircraft) campaigns (PGS). Starting from Oberpfaffenhofen, Germany, or from Kiruna, Sweden, 18 research flights were carried out by the German research aircraft HALO (High Altitude and LOng range research aircraft) between December 2015 and March 2016. The flights probed an entire winter period in the LMS at high northern latitudes. For this study five research flights between December and March were used. The selection of the flight data was based on data availability and scientific requirements. Data availability was limited to flight sections where GLORIA was operated in the high spectral resolution "chemistry mode" (Friedl-Vallon et al., 2014) used in this study (see Sect. 2.2) and sufficiently cloud-free conditions allowing for the retrieval of $\mathrm{HNO}_{3}$. From the scientific point of view, flights with long continuous chemistry mode measurements were chosen to show how patterns in the lowermost stratospheric $\mathrm{HNO}_{3}$ distribution change during the winter. We furthermore focus on flights in January, where PSCs reached down to the LMS and where the most notable changes are found in the observed $\mathrm{HNO}_{3}$ distributions. Since we use ozone as stratospheric tracer to quantify nitrification, flights in January are preferable since only little chemical ozone loss was diagnosed at this time of the winter when compared to February and March (see Johansson et al., 2019). Further GLORIA chemistry mode observations can be found in the supplementary information of Johansson et al. (2018a) and at the HALO Database (https://halo-db.pa.op.dlr.de/, last access: 4 November 2019).

\subsection{GLORIA}

GLORIA is an airborne infrared limb imaging spectrometer (Friedl-Vallon et al., 2014). During PGS, GLORIA has been operated on board the HALO aircraft and pointed to the right-hand side of the flight path. GLORIA combines a Michelson interferometer with an imaging $\mathrm{HgCdTe}$ detector which records 128 vertical and 48 horizontal interferograms simultaneously. All interferograms are transformed into spectra. The spectra from horizontal detector rows are averaged for noise reduction prior to the atmospheric parameter retrieval (Kleinert et al., 2014). In high spectral resolution mode, which is used in this study, the spectrometer covers the range from 780 to $1400 \mathrm{~cm}^{-1}$ with a spectral sampling of $0.0625 \mathrm{~cm}^{-1}$. For the retrieval, the radiative transfer code KOPRA (Karlsruhe Optimized and Precise Radiative transfer Algorithm; Stiller et al., 2002) and the inversion tool KOPRAFIT (Höpfner et al., 2001) were used. Estimated uncertainties of the GLORIA retrieval results are typically 1$2 \mathrm{~K}$ for temperature and $10 \%-20 \%$ for trace gases. Typical vertical resolutions of the retrieved profiles are about $400 \mathrm{~m}$ at flight altitude and decrease to about $1000 \mathrm{~m}$ around the lowest tangent points. A detailed description and validation of the dataset used in this study is given by Johansson et al. (2018a).

\subsection{CLaMS}

The Chemical Lagrangian Model of the Stratosphere (CLaMS) (McKenna, 2002a, b) is a chemistry transport model based on trajectory calculations for an ensemble of air parcels. CLaMS includes modules simulating Lagrangian trajectories, mixing, chemical processes and Lagrangian particle sedimentation. The CLaMS simulations used here were performed with a special setup for the POLSTRACC campaign with a horizontal resolution of about $100 \mathrm{~km}$ and a vertical resolution of about $500-900 \mathrm{~m}$ in the lower stratosphere above $10 \mathrm{~km}$ altitude decreasing to about $2 \mathrm{~km}$ below $9 \mathrm{~km}$ altitude. Further, this configuration includes a comprehensive stratospheric chemistry as described by Grooß et al. (2014). The simulations were performed for the entire winter and were based on meteorological wind and temperature data from the ECMWF ERA interim reanalysis (Dee et al., 2011) employing a horizontal resolution of 1 degree $\times 1$ degree and a time step of $6 \mathrm{~h}$. To simulate processes connected to NAT particles, particle parcels are implemented (Grooß et al., 2005, 2014). Particle size and number concentration 
are assigned to each particle parcel so that various particle parcels in one air parcel determine the particle size distribution. NAT and ice nucleation is temperature and saturation dependent and is parameterized by the scheme by Hoyle et al. (2013) and Engel et al. (2013), respectively. Particle growth and evaporation are calculated along particle trajectories based on Carslaw (2002) assuming the characteristics of spherical particles (Tritscher et al., 2019). Comparisons with PSC observations (Tritscher et al., 2019) show that the parametrization of nucleation and sedimentation of NAT and ice particles in CLaMS is capable to reproduce the main features of PSC observations. Also, vortex averages of the vertical redistribution of $\mathrm{HNO}_{3}$ and $\mathrm{H}_{2} \mathrm{O}$ have been reproduced (Tritscher et al., 2019).

\section{Methods}

\subsection{GLORIA vertical cross sections of atmospheric parameters}

The GLORIA retrieval results in vertical profiles of atmospheric parameters. These vertical profiles are combined to two-dimensional quasi-vertical cross sections along the flight paths and show mesoscale atmospheric structures (Johansson et al., 2018a). Since the observations are performed in limb mode, the distance of the tangent points (i.e where the major information about atmospheric parameters stems from) gradually increases from the observer for the lower limb views. This is reflected by the tangent point distributions discussed in Sect. 4.1 to 4.3. The GLORIA data are filtered for cloudaffected observations, and data points with a vertical resolution worse than $2 \mathrm{~km}$ or above flight altitude are neglected for further analysis.

\subsection{Simulated cross sections from CLaMS}

For comparison with GLORIA, the CLaMS data were interpolated to the retrieval grid geolocations, characterized by altitude, latitude, longitude and time of the tangent points. The temporal interpolation with respect to atmospheric dynamics is performed by trajectory calculations. CLaMS output is typically saved daily at 12:00 UTC. Therefore forward trajectories are calculated for points between 00:00 and 12:00 until 12:00 UTC. The corresponding 12:00 UTC volume mixing ratio is then assumed as concentration of the original geolocation based on the assumption that chemical and physical changes in volume mixing ratios during the time of the trajectory calculations are negligible for the chemical species considered here. For points between 12:00 and 00:00 UTC backward trajectories are calculated analogously.

\subsection{Identification of sub-vortex air}

The altitude range of GLORIA observations in this study typically lies within the LMS, ranging from the tropopause to the $380 \mathrm{~K}$ isentrope (see Werner et al., 2010, and references therein). It has to be pointed out that robust identification of vortex air in the LMS is not possible due to dynamical disturbances, transport and in-mixing of air masses from different origins. In fact, the sub-vortex region in the LMS has a more filamentary character and is affected by interaction with air masses from the extra-vortex stratospheric overworld, the extra-tropical transition layer (ExTL) and the troposphere (Gettelman et al., 2011). Two filters have been applied to select data points associated with the sub-vortex region.

The first filter applied is the criterion by Nash et al. (1996) at the $370 \mathrm{~K}$ isentrope and is based on the potential vorticity (PV) field obtained from the MERRA-2 reanalysis (Gelaro et al., 2017). Grid points with latitude-longitude pairs outside the polar vortex at the potential temperature $(\theta)$ level of $370 \mathrm{~K}$ are classified as non-vortex points. Secondly, data are filtered by scaled potential vorticity (sPV) calculated from MERRA-2 reanalysis data with a threshold of $1.2 \times 10^{-4} \mathrm{~s}^{-1}$. $\mathrm{sPV}$ is calculated by dividing the potential vorticity (PV) by $\partial \theta / \partial p$ to obtain similar PV ranges for all isentropic levels that are investigated (Manney et al., 1994; Dunkerton and Delisi, 1986). Therefore this filter takes the altitude information of the grid points into account. Data points in the tracer correlations (see below) are attributed to sub-vortex air, if both criteria are met.

\subsection{Quantification of nitrification based on tracer-tracer correlations using relative normalized frequency distributions}

To quantify nitrification in the LMS tracer-tracer correlations of $\mathrm{HNO}_{3}$ and $\mathrm{O}_{3}$ associated with sub-vortex air are analysed. Here, we use ozone as an approximation of a passive reference tracer, since ozone is well accessible with GLORIA and shows a sufficient vertical gradient in the LMS region. The choice of ozone as a passive tracer is based on the assumption that ozone depletion is small in January as the air is hardly exposed to sunlight. The model study by Khosrawi et al. (2017) supports this assumption. Two aspects can affect the correlation: (1) mixing with extra-vortex air masses not affected by nitrification would lead to an underestimation of $\mathrm{HNO}_{3}$ introduced into the LMS by nitrification and (2) potential ozone depletion would shift higher $\mathrm{HNO}_{3}$ mixing ratios to lower ozone values, thus enhancing estimated nitrification.

As correlation scatter plots of measured data for several flights are difficult to assess due to the large number of individual points, estimates of relative normalized frequency distributions (RNFDs), as described by Eckstein et al. (2018), are used in this study. This method calculates a scaled twodimensional histogram on a volume mixing ratio grid. In this study a grid of $0.070 \mathrm{ppmv} \mathrm{O}_{3} \times 0.35 \mathrm{ppbv} \mathrm{HNO}_{3}$ is chosen, which is motivated by the total estimated error of the trace gases (Johansson et al., 2018a). GLORIA data points with 


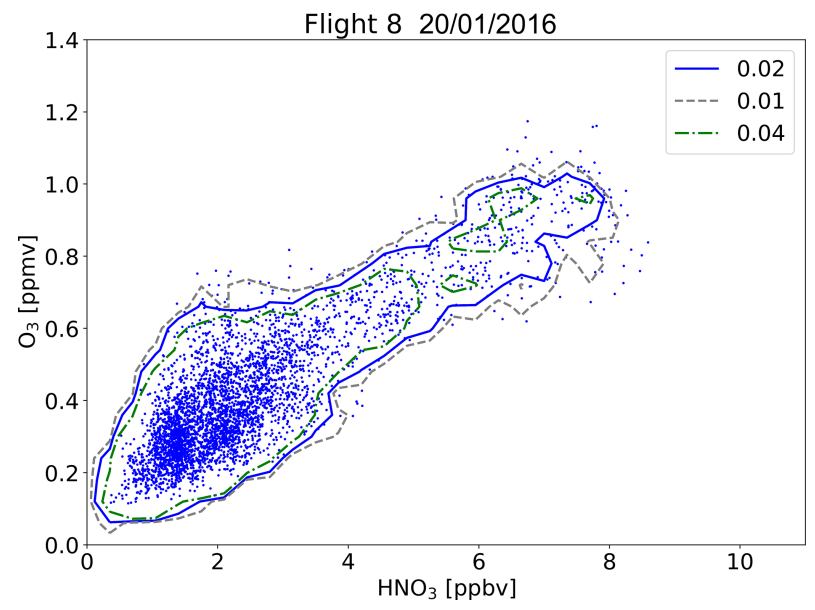

Figure 1. Correlation of $\mathrm{HNO}_{3}$ with $\mathrm{O}_{3}$ measured by GLORIA during flight 8 on 20 January 2016. The correlation is shown as single points and as a RNFD (solid, dashed and dash-dotted lines; see legend).

a calculated relative error larger than $20 \%$ are neglected in this study. Besides a clearer presentation of the data points, RNFDs filter out single data points with very high $\mathrm{HNO}_{3}$ volume mixing ratios. Therefore, in the context of a challenging vortex identification, this method offers an additional filter, as single data points that are differing significantly and are erroneously identified as vortex air are filtered out. Here it has to be pointed out that also local non-erroneous points with very high $\mathrm{HNO}_{3}$ values within the vortex are filtered out applying this method. However, in this study we aim to quantify the overall nitrification of the LMS, while local nitrification is highly inhomogeneous and can reach significantly higher values. The RNFD contour line used for quantification in this study includes points within $2 \%$ of the histograms maximum density. An example of a RNFD for the $\mathrm{HNO}_{3}-\mathrm{O}_{3}$ correlation during flight 8 is given in Fig. 1. We also show alternative isolines including $1 \%$ and $4 \%$ of the maximum density of the histogram to visualize weaker and stronger thresholds for statistical outliers. In all cases, the isolines show a similar pattern in general. However, stronger threshold values limit the vertical range of the analysis and filter out valuable significant data points.

\section{GLORIA observations and CLaMS simulations of selected flights from January to March 2016}

To investigate how the observed $\mathrm{HNO}_{3}$ distribution is affected by nitrification, three research flights have been selected. The first flight was carried out on 20 January 2016 during the coldest phase of the winter (Manney and Lawrence, 2016), with PSCs ranging down to flight level. The second flight took place on 31 January 2016 after a strong PSC phase. The last flight was carried out on
18 March 2016 at a late state of the winter - about 2 weeks after the final warming (5-6 March; Manney and Lawrence, 2016).

The observed patterns in the $\mathrm{HNO}_{3}$ distributions are compared with the observed patterns in the ozone distribution. Since ozone and $\mathrm{HNO}_{3}$ are effected by the same dynamical processes, the different patterns in the observed distributions are likely caused by processes that effect only one species (i.e. nitrification due to sublimation of $\mathrm{NO}_{y}$-containing particles sedimented from higher altitudes). Therefore, the local $\mathrm{HNO}_{3}$ enhancements seen in comparing adjacent air masses at a given height level and the deviations of their pattern from the pattern seen in the ozone distribution are interpreted qualitatively as a result of nitrification.

\subsection{Flight 8 on 20 January 2016}

Applying the Nash criterion on 20 January 2016, a relatively coherent vortex region is found, with all GLORIA tangent points located inside the vortex region at $\theta=370 \mathrm{~K}$ (Fig. 2a). Since clouds complicate a robust trace gas retrieval, a number of GLORIA observations were removed by cloud filtering. As a consequence, only limited GLORIA nitric acid data are available in flight sections with sufficiently transparent conditions (Fig. 2b). Further, particulate $\mathrm{NO}_{y}$ (i.e. the difference between measured total $\mathrm{NO}_{y}$ and gas-phase $\mathrm{NO}_{y}$ ) was simultaneously measured in situ by using a chemiluminescence detector in combination with a converter for $\mathrm{NO}_{y}$ species (Stratmann et al., 2016). Similar observations have also been made during other aircraft campaigns in the Arctic (Northway et al., 2002).

The measurements shown in Fig. $2 \mathrm{c}$ are based on the subisokinetic sampling of particles with a forward-looking inlet (e.g. Fahey et al., 1989; Ziereis et al., 2004). Particles larger than a few tenths of a micrometre are sampled with enhanced efficiency and are detected as gas-phase equivalent $\mathrm{NO}_{y}^{*}$. The efficiency factor depends, among others, on the ratio between aircraft and sampling velocity, pressure, temperature, and particle size (e.g. Fahey et al., 1989; Feigl et al., 1999). The maximum enhancement factor may be achieved for particle sizes larger than about $10 \mu \mathrm{m}$ and is on the order of several tens, depending on the actual combination of the above mentioned parameters. Here, only equivalent $\mathrm{NO}_{y}^{*}$ that was not corrected for enhancement is shown as a qualitative proxy for particulate $\mathrm{HNO}_{3}$. As absolute values cannot be obtained, we only use the data as a proxy for condensed $\mathrm{HNO}_{3}$-containing particles present at flight altitude. The in situ data clearly confirm the presence of $\mathrm{HNO}_{3}$-containing PSC particles at flight altitude and mainly between waypoints $\mathrm{A}$ and $\mathrm{B}$ in close vicinity to gas-phase $\mathrm{HNO}_{3}$ maxima detected by GLORIA.

The vertical cross sections of $\mathrm{O}_{3}$ and $\mathrm{HNO}_{3}$ volume mixing ratios along the HALO flight track derived from GLORIA are depicted in Fig. $2 b$ and d. The ozone distribution shows increasing volume mixing ratios with altitude reach- 

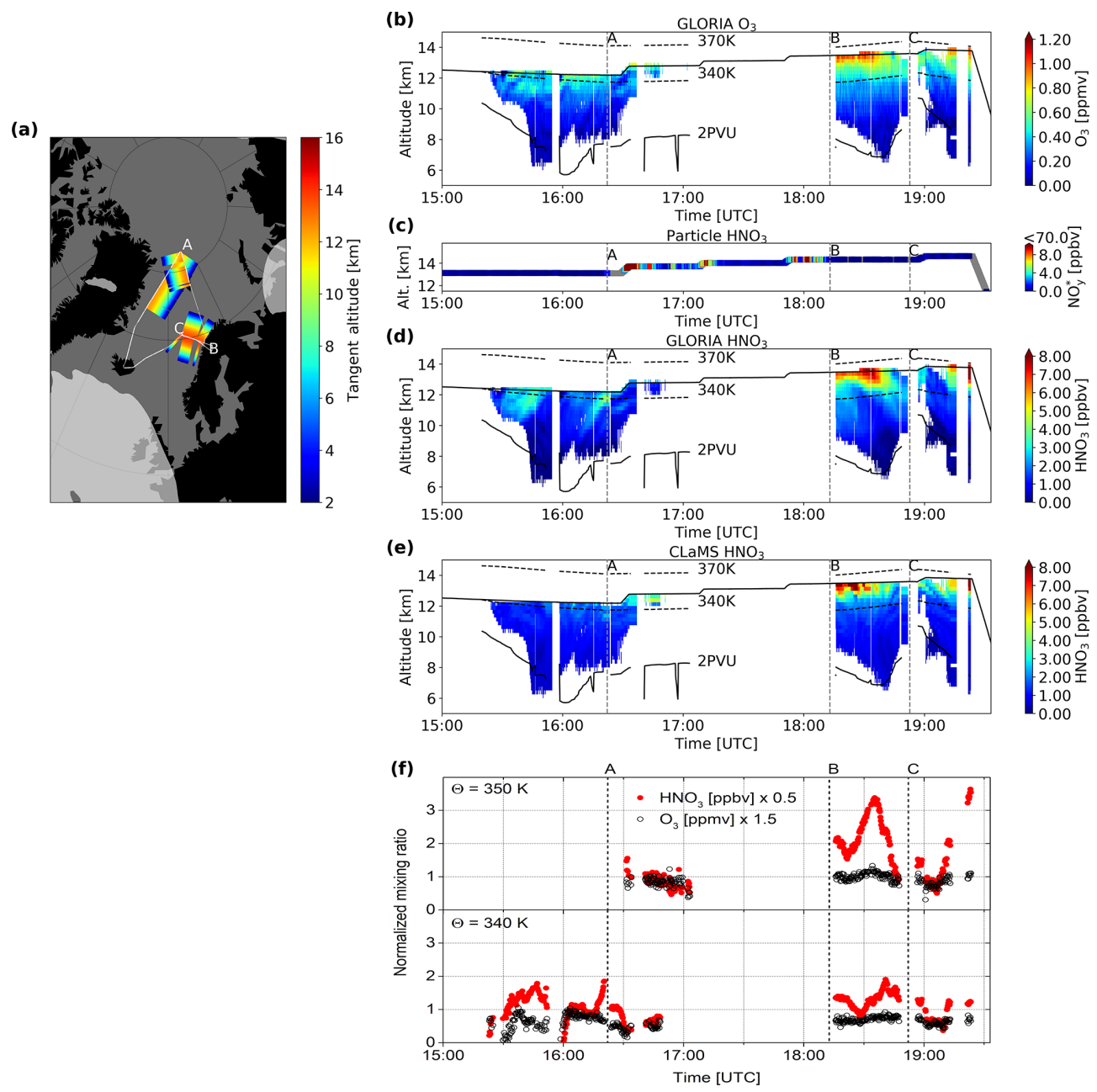

Figure 2. (a) Flight path and vortex filtering according to the Nash criterion at $370 \mathrm{~K}$ for flight 8 on 20 January 2016 . White line: flight track with characteristic waypoints $(\mathrm{A}, \mathrm{B}, \mathrm{C})$; dark grey shading: areas that are associated with the polar vortex. (b) Cross section of $\mathrm{O}_{3}$ distribution derived from GLORIA. Flight altitude (bold black line), characteristic waypoints (A, B, C), 340 and $370 \mathrm{~K}$ potential temperature levels (MERRA-2, dashed black lines), and 2 PVU level (MERRA-2, black line). (c) In situ measurements of gas-phase equivalent NO* (not enhancement corrected) as a proxy for particulate $\mathrm{HNO}_{3}$ at flight altitude. (d) Cross section of $\mathrm{HNO}_{3}$ distribution derived from GLORIA and (e) $\mathrm{HNO}_{3}$ distribution simulated by CLaMS. Flight altitude (bold black line), characteristic waypoints (A, B, C), 340 and $370 \mathrm{~K}$ potential temperature levels (MERRA-2, dashed black lines), and 2 PVU level (MERRA-2, black line). (f) Normalized $\mathrm{HNO}_{3}$ and $\mathrm{O}_{3}$ mixing ratios along selected isentropes. The whole flight was carried out in air masses attributed to the sub-vortex region.

ing $1.1 \mathrm{ppmv}$ at $13 \mathrm{~km}$. The observed $\mathrm{O}_{3}$ volume mixing ratios vary only moderately at fixed altitude levels during the whole flight in agreement with the location of the measurements within the vortex and the homogeneity inside the vortex. Compared to the ozone distribution, the $\mathrm{HNO}_{3}$ volume mixing ratios are varying significantly at fixed altitudes. The $\mathrm{HNO}_{3}$ distribution shows high $\mathrm{HNO}_{3}$ volume mixing ratios particularly in the flight segment between the waypoints B and $\mathrm{C}$, reaching up to $8 \mathrm{ppbv}$ at a flight altitude of $13 \mathrm{~km}$ compared to 3 ppbv observed in adjacent air around waypoint $C$. Differences of this maximum structure from the corresponding $\mathrm{O}_{3}$ distribution are interpreted qualitatively as nitrified air. Further, local maxima are forming coherent structures tilted with altitude and are observed down to $11 \mathrm{~km}$ in that flight segment. In addition, small-scale fine structures with enhanced $\mathrm{HNO}_{3}$ volume mixing ratios appear between 15:30 and 17:00 UTC and reach down to $10 \mathrm{~km}$. The pattern of continuous and slightly tilted vertical bands differ significantly from the ozone distribution and show enhanced values compared to adjacent air masses at a given height level, thus suggesting their formation by redistribution of $\mathrm{HNO}_{3}$.

To test this hypothesis, we show normalized GLORIA $\mathrm{HNO}_{3}$ and $\mathrm{O}_{3}$ data along selected isentropes in Fig. 2f. Normalization factors are chosen in a way such that the mixing ratios of both gases are close to 1 in air masses which are not affected by nitrification. In particular, $\mathrm{HNO}_{3}$ volume mixing ratios (in ppbv) were multiplied by a constant factor of 0.5 , and $\mathrm{O}_{3}$ volume mixing ratios (in ppmv) were multiplied 
by a constant factor of 1.5 to result in the shown unitless normalized mixing ratios. The same factors were applied for the subsequent flights. In unaffected air masses, the normalized mixing ratios of these gases are expected to show the same pattern. In nitrified air masses, locally enhanced $\mathrm{HNO}_{3}$ and different modulations are expected relative to $\mathrm{O}_{3}$. In fact, such local maxima in the $\mathrm{HNO}_{3}$ mixing ratios can be identified at $340 \mathrm{~K}$ around 15:45, 16:25, 18:20 and 18:40 UTC, and are more pronounced at $350 \mathrm{~K}$ around 18:35 and after 19:10 UTC. The maxima clearly coincide with local maxima seen in the $\mathrm{HNO}_{3}$ cross sections. Thus, the simultaneous presence of confined local gas phase $\mathrm{HNO}_{3}$ maxima in the GLORIA data and $\mathrm{HNO}_{3}$-containing particles detected in situ in regions close to the equilibrium temperature of NAT, well above the equilibrium temperature of ice (see GLORIA temperature data shown in Johansson et al., 2018a), suggests that an ongoing nitrification process was probed.

The vertical cross section of $\mathrm{HNO}_{3}$ volume mixing ratios modelled by CLaMS is shown in Fig. 2e. $\mathrm{HNO}_{3}$ volume mixing ratios reach maximum values of $8 \mathrm{ppbv}$ at flight altitude in the flight segment between $\mathrm{B}$ and $\mathrm{C}$. While maximum $\mathrm{HNO}_{3}$ volume mixing ratios in this flight are well represented by CLaMS, slight differences in the location of the maximum occur. Overall $\mathrm{HNO}_{3}$ mixing ratios are clearly underestimated by CLaMS, and CLaMS mostly misses the vertical fine structure.

\subsection{Flight 12 on 31 January 2016}

At the end of January 2016, applying the Nash criterion at $\theta=370 \mathrm{~K}$, a more disturbed lower vortex region is observed. As shown in Fig. 3a, a large region between Greenland, central Europe and northern Siberia fulfilled the vortex criterion. However, filaments of lower PV are found from Greenland to southern Scandinavia and around the eastern rim of Scandinavia. Flight 12 was carried out starting and ending in Kiruna on 31 January and intersected several times with filaments outside the vortex.

Measured cross sections of $\mathrm{O}_{3}$ and $\mathrm{HNO}_{3}$ volume mixing ratios are depicted in Fig. $3 b$ and c. Except for flight segments between 08:40 and 09:20 UTC, as well as between 11:30 and 11:50 UTC, that are associated with the vortex edge or non-vortex air (indicated by grey shading in Fig. 3be), ozone values increasing with height are observed. Compared to the ozone values only varying slightly along an isentrope, the $\mathrm{HNO}_{3}$ volume mixing ratios show larger variations at levels of constant potential temperature and suggest local enhancements by nitrification. Again, the analysis of normalized $\mathrm{HNO}_{3}$ and $\mathrm{O}_{3}$ along the selected isentropes clearly shows enhanced and more variable $\mathrm{HNO}_{3}$ mixing ratios relative to $\mathrm{O}_{3}$ inside air masses attributed to the sub-vortex region (Fig. 3e, for normalization see Sect. 4.1). During this flight, high local maximum values of $\mathrm{HNO}_{3}$ well above 10 ppbv are found between 13:30 and 14:30 UTC in the GLORIA observations.
The $\mathrm{HNO}_{3}$ distribution modelled by CLaMS is shown in Fig. 3d. When compared to GLORIA, locally more confined and weaker $\mathrm{HNO}_{3}$ maxima are modelled after 12:15 UTC reaching down to altitudes of $12 \mathrm{~km}$. Maximum $\mathrm{HNO}_{3}$ volume mixing ratios are found at flight altitude showing narrow peaks up to $10 \mathrm{ppbv}$ at 12:15 UTC and $8 \mathrm{ppbv}$ at 12:50 UTC, at waypoints $\mathrm{C}$ and D. Overall, CLaMS shows a higher spatial variability and underestimates the maximum values during large parts of the flight.

\subsection{Flight 21 on 18 March 2016}

For the flight on 18 March 2016, the PV distribution shows a patchy pattern of regions inside the remains of the vortex according to Nash et al. (1996) around Scandinavia, with the GLORIA observations being located partly inside and outside these regions (Fig. 4a).

The measured $\mathrm{O}_{3}$ distribution (Fig. 4b) shows increasing values with altitude and reaches values of $1.2 \mathrm{ppmv}$ at flight level. Ozone values along the isentropes vary only slightly. The measured $\mathrm{HNO}_{3}$ distribution (Fig. 4c) shows a slightly higher variability along the isentropes with local maxima for altitudes higher than $9 \mathrm{~km}$ reaching maximum values of up to $6 \mathrm{ppbv}$ at flight altitude embedded in background values of 2 to 3 ppbv. Filamentation and mixing following the earlier vortex break-up (Manney and Lawrence, 2016) resulted in less spatial variability when compared to the previous flights. Since flight 21 was carried out after the vortex break-up and the correlation of $\mathrm{HNO}_{3}$ and $\mathrm{O}_{3}$ was altered by in-mixing of extra-vortex air, this flight is included in the model comparisons in Sect. 6 but not in the quantification of nitrification of the LMS in Sect. 5. However, well-defined local maxima qualitatively attributed to result from nitrification by the comparison with the ozone distribution still persisted in this late stage of the winter. The analysis of normalized $\mathrm{HNO}_{3}$ and $\mathrm{O}_{3}$ along isentropes shows enhanced and slightly more variable $\mathrm{HNO}_{3}$ mixing ratios relative to $\mathrm{O}_{3}$ in the sub-vortex region and its vicinity, thus supporting that these patterns are remnants of nitrification (Fig. 4e, for normalization see Sect. 4.1).

CLaMS (Fig. 4d) shows $\mathrm{HNO}_{3}$ volume mixing ratios for altitudes higher than $9 \mathrm{~km}$ corresponding well with GLORIA observations. Maximum values of locally $6 \mathrm{ppbv}$ are modelled around 12:30 UTC at $13 \mathrm{~km}$. Again, CLaMS slightly underestimates overall $\mathrm{HNO}_{3}$ mixing ratios when compared to GLORIA.

\section{Quantification of nitrification of the LMS from December 2015 to January 2016}

To quantify nitrification in the LMS from December 2015 to January 2016 we applied the method described in Sect. 3.4 using selected flights in this period. Figure 5 a depicts the distributions for flights 5, 6, 8 and 12 derived from GLORIA 

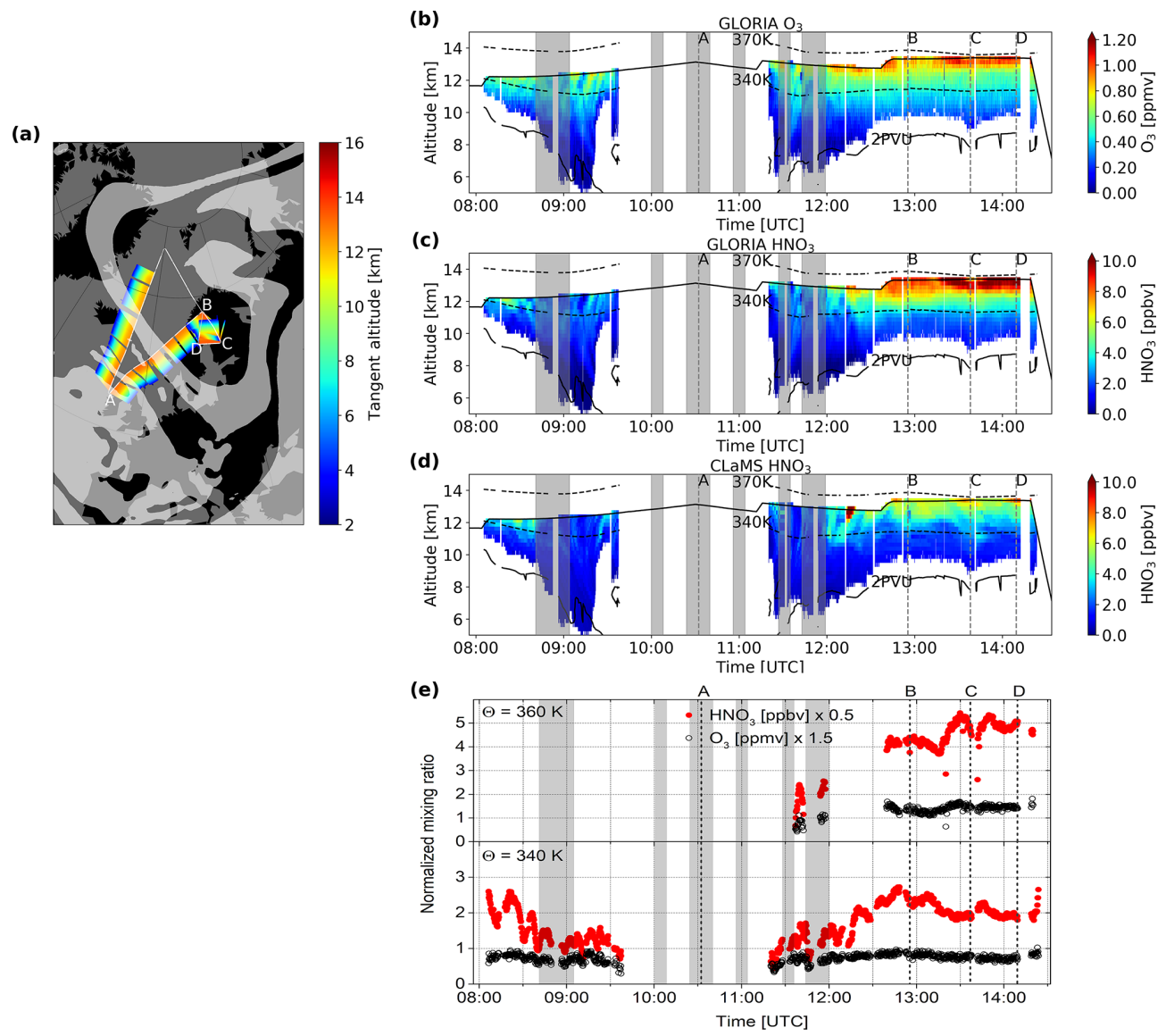

Figure 3. (a) Flight path and vortex filtering according to the Nash criterion at $370 \mathrm{~K}$ for flight 12 on 31 January 2016 . White line: flight track with characteristic waypoints $(\mathrm{A}, \mathrm{B}, \mathrm{C}, \mathrm{D})$; dark grey shading: areas that are associated with the polar vortex. Cross sections of (b) $\mathrm{O}_{3}$ and (c) $\mathrm{HNO}_{3}$ distribution derived from GLORIA and (d) $\mathrm{HNO}_{3}$ distribution simulated by CLaMS. Flight altitude (bold black line), characteristic waypoints (A, B, C, D), 340 and $370 \mathrm{~K}$ potential temperature levels (MERRA-2, dashed black lines), and 2 PVU level (MERRA-2, black line). Please note the changed colour bar for $\mathrm{HNO}_{3}$ compared to Figs. 2 and 4. (e) Normalized $\mathrm{HNO}_{3}$ and $\mathrm{O}_{3}$ mixing ratios along selected isentropes. Passages attributed to non-sub-vortex air are shaded in grey.

observations. Flight 5 (only limited GLORIA data available, see Appendix A) was carried out on 21 December 2015, at the beginning of the winter, with no significant hints to nitrification. Therefore this flight was chosen as the early winter reference. Due to a limited number of points associated with vortex air and since sub-vortex and non-vortex data points show a compact correlation for flight 5 , non-vortex points are also included here to extend the available data. For all other flights, only data points associated with vortex air are used. Flight 6 (see Appendix A) covered a broad range of latitudes in the sub-vortex region and below PSCs (Pitts et al., 2018).

$\mathrm{HNO}_{3}$ volume mixing ratios for flight 5 range up to $3.2 \mathrm{ppbv}$ with an approximately linear relationship to the observed ozone values. In case of flight 6 , enhanced $\mathrm{HNO}_{3}$ volume mixing ratios compared to flight 5 are observed for all ozone values. Flight 8 shows a similar enhancement throughout the whole range of ozone mixing ratios observed. While the enhancement is similar to flight 6 , minimum $\mathrm{HNO}_{3}$ values for ozone values higher than $0.7 \mathrm{ppmv}$ are higher than those for the flights before. For flight 12, the $\mathrm{HNO}_{3}$ volume mixing ratios reach higher values than those for the previous flights. Altogether, comparing maximum values with the early winter reference, an ongoing nitrification is observed between December 2015 and January 2016 reaching up to $7 \mathrm{ppbv}$ at ozone values of $1 \mathrm{ppmv}$ and $5 \mathrm{ppbv}$ at ozone values of 0.6 ppmv.

Johansson et al. (2019) estimated an ozone depletion by $0.15 \mathrm{ppmv}$ at $380 \mathrm{~K}$ for ozone values around $1.15 \mathrm{ppmv}$ by the end of January 2016. Assuming this potential ozone depletion of $15 \%$ (dashed profile in Fig. 5a) in the LMS during the given time frame, the estimated nitrification would reduce to $6 \mathrm{ppbv}$ at $1 \mathrm{ppmv} \mathrm{O}_{3}$ and $3.5 \mathrm{ppbv}$ at ozone values of 0.6 ppmv. This is a lower-limit estimation, especially considering the contrary effect by mixing of non-vortex air masses.

Correlation-based approaches are also suitable for model comparisons. The exact reproduction of complex fine structures by models cannot be expected because of uncertainties in measurements and the model. Differences in the meteo- 

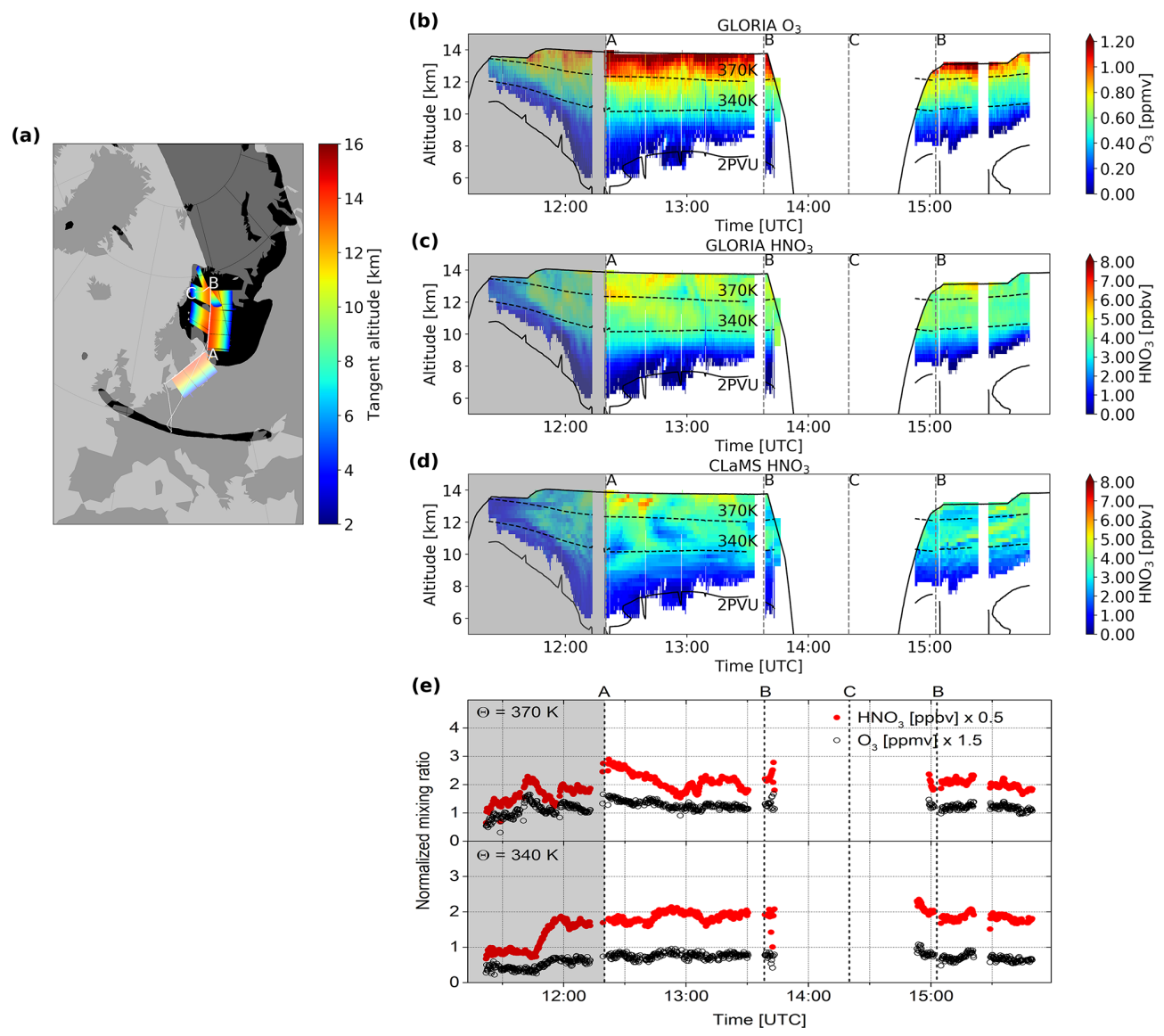

Figure 4. (a) Flight path and vortex filtering according to the Nash criterion at $370 \mathrm{~K}$ for flight 21 on 18 March 2016 . White line: flight track with characteristic waypoints $(\mathrm{A}, \mathrm{B}, \mathrm{C})$; dark grey shading: areas that are associated with the polar vortex. Cross sections of (b) $\mathrm{O}_{3}$ and (c) $\mathrm{HNO}_{3}$ distribution derived from GLORIA and (d) $\mathrm{HNO}_{3}$ distribution simulated by CLaMS for flight 21. Flight altitude (bold black line), characteristic waypoints (A, B, C), 340 and $370 \mathrm{~K}$ potential temperature levels (MERRA-2, dashed black lines), and 2 PVU level (MERRA-2, black line). (e) Normalized $\mathrm{HNO}_{3}$ and $\mathrm{O}_{3}$ mixing ratios along selected isentropes. The passage attributed to non-sub-vortex air is shaded in grey.

rological fields used for modelling, especially the temperature, can result in differing local structures. Since the investigated flights probed a wide range of the sub-vortex region, the obtained correlations can be regarded as representative for the (Arctic) sub vortex and allows the comparison between model and measurement. We point out that observed differences in RNFDs can be caused by an inaccurate representation of processes influencing both $\mathrm{HNO}_{3}$ and $\mathrm{O}_{3}$ volume mixing ratios.

The distributions simulated by CLaMS are shown in Fig. 5b. For flight 5, the $\mathrm{HNO}_{3}$ volume mixing ratios range up to $2.5 \mathrm{ppbv}$ in an approximately linear relationship. Flight 6 shows enhanced $\mathrm{HNO}_{3}$ volume mixing ratios that are significantly lower than those for the GLORIA observations. CLaMS models a further enhancement for flight 8 with a small patch reaching the maximum values observed by GLORIA. Similar to the GLORIA measurements, flight 12 displays the highest $\mathrm{HNO}_{3}$ volume mixing ratios of all flights. However, the maximum values observed by CLaMS are 2 ppbv lower. Beneath 0.3 ppmv $\mathrm{O}_{3}$ hardly any enhancement is observed over the duration of the flights. Overall, CLaMS is able to reproduce the general enhancement of $\mathrm{HNO}_{3}$ during the winter leading to a nitrification of up to $4 \mathrm{ppbv}$ for ozone values of 0.8 to $1 \mathrm{ppmv}$, which is by $3 \mathrm{ppbv}$ $\mathrm{HNO}_{3}$ lower than the GLORIA observations.

\section{Comparison of GLORIA results with CLaMS sensitivity simulations}

Four sensitivity simulations have been performed to investigate processes and aspects that have not been represented in the model so far. These sensitivity simulations were performed based on assumptions concerning particle formation and shape. Besides the formation of NAT on ice particles, ice can possibly accumulate on NAT particles (Voigt et al., 2018) resulting in larger particles with an enhanced settling velocity. Therefore in the "ice settling" simulation the computed 
(a)

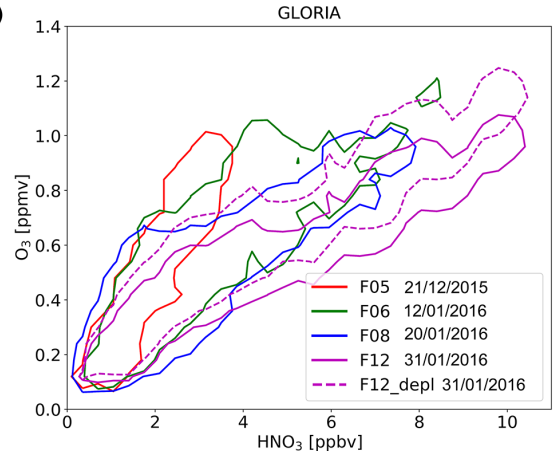

(b)

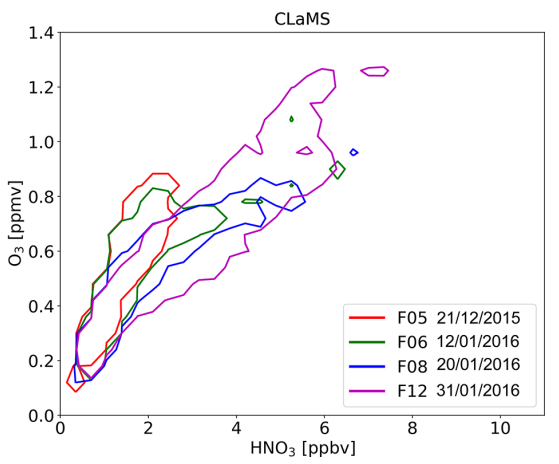

Figure 5. Isolines (contours at 0.02) of the normalized frequency distribution of the $\mathrm{O}_{3}-\mathrm{HNO}_{3}$ correlation for December $2015-\mathrm{January} 2016$ derived from (a) GLORIA measurements and (b) CLaMS simulations. The dashed line for flight 12 includes a compensation of a potential ozone loss of $15 \%$.

ice settling velocity (computed as described by Tritscher et al., 2019) was increased by a factor of 1.5 at all locations where the saturation ratio of ice, $S_{\text {Ice }}$, is larger than 1.2. Since NAT formation is temperature dependent, a sensitivity simulation is performed with a global temperature offset of $1 \mathrm{~K}$. Particle growth in CLaMS is based on the assumption of growth rates of spherical particles. However, Woiwode et al. (2016) found indications for highly aspherical particles with an enhanced surface compared to spherical particles of the same volume. Since the $\mathrm{HNO}_{3}$ uptake depends on the surface, a faster particle growth would occur. A 1.5 times enhanced particle growth was implemented in the "aspherical particle" simulation. Changes in settling velocities due to different shapes have not been taken into account here. Several studies suggest a connection between orographically induced gravity waves and NAT formation (Davies et al., 2005; Carslaw et al., 1998; Höpfner et al., 2006). However smallscale temperature fluctuations are not resolved by ERA interim temperatures. Therefore, artificial fluctuations according to Tritscher et al. (2019) have been added in the "temperature fluctuations" simulation.

The comparison is based on the RNFDs depicted for the individual flights in Fig. 6. The model cross sections compared to measurements of flights $6,8,12$ and 21 can be found in the Appendix B (Figs. B1, B2, B3, B4).

The ice settling simulation (yellow) delivers nearly identical results as the reference simulation for all flights. For the "T-1K" simulation (dark blue), enhanced $\mathrm{HNO}_{3}$ volume mixing ratios are observed down to lower $\mathrm{O}_{3}$ volume mixing ratios compared to the reference simulations for flight 6 and 8 , but they are still not reaching down to the ozone values noticed by GLORIA. The high $\mathrm{HNO}_{3}$ volume mixing ratios measured by GLORIA are still underestimated here. While there are only slight changes compared to the reference simulation for flight 12 , the $\mathrm{T}-1 \mathrm{~K}$ simulation is clearly deteriorating for flight 21 . Here, lower ozone volume mixing ratios are observed. For this flight none of the CLaMS simulations are able to reproduce the high ozone volume mixing ratios ob- served by GLORIA, which is possibly caused by weaker subsidence in the model. Further, lower absolute $\mathrm{HNO}_{3}$ values might occur due to stronger mixing in CLaMS. The aspherical particle case results in enhanced values observed down to lower altitudes than for the reference simulation for the flights 6,8 and 12. Further, it shows higher maximum $\mathrm{HNO}_{3}$ values than for the reference for flights 6 and 8 . However, the absolute values are still underestimated compared to the GLORIA observations. For the flights 12 and 21, indications for points with lower $\mathrm{HNO}_{3}$ values compared to the reference are found. The RNFD structure of temperature fluctuation simulation for flight 6 and 21 are nearly identical to the reference simulation. For flight 8 , lower $\mathrm{HNO}_{3}$ volume mixing ratios are observed. In contrast to that, the temperature fluctuation simulation for flight 12 shows the best agreement with the observations. However, even though the lower branch is consistent with GLORIA, an upper branch with values lower than the reference simulation and far lower than GLORIA exists.

\section{Discussion and conclusion}

Nitrification of the LMS in the Arctic winter 2015-2016 was analysed based on GLORIA measurements during the PGS campaign. Vertical cross sections of $\mathrm{HNO}_{3}$ volume mixing ratios for several flights throughout the winter show complex fine-scale structures and enhanced values at altitudes down to $9 \mathrm{~km}$. Flight 8 on 20 January 2016 was carried out under cold conditions with PSC observations at flight altitude. For this flight, coherent structures tilted with altitude of locally enhanced $\mathrm{HNO}_{3}$ volume mixing ratios are observed that most likely indicate defined regions where settled $\mathrm{HNO}_{3}$-containing particles recently sublimated. This is supported by simultaneous in situ observations of $\mathrm{HNO}_{3}$ containing particles. The net effect of proceeding nitrification and dynamical processes in the LMS is observed for flight 12 at the end of January with a pronounced pattern of enhanced $\mathrm{HNO}_{3}$ volume mixing ratios well exceeding $10 \mathrm{ppbv}$. Nitri- 

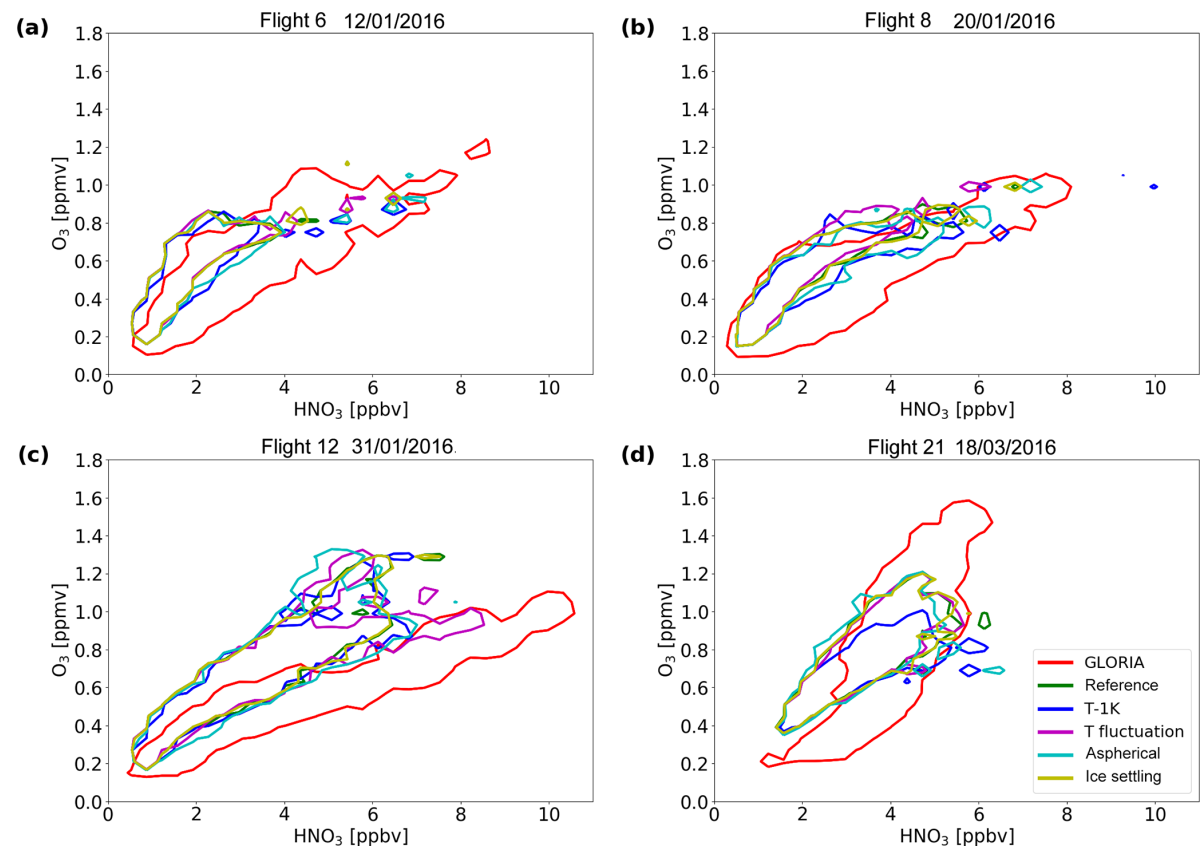

Figure 6. Isolines (contours at 0.02) of the normalized frequency distribution of the $\mathrm{O}_{3}-\mathrm{HNO}_{3}$ correlation for (a) flight 6 on 12 January 2016 , (b) flight 8 on 20 January 2016, (c) flight 12 on 31 January 2016, (d) flight 21 on 18 March 2016 derived from GLORIA measurements (red) and CLaMS simulations. The reference in the panels corresponds to model reference run without perturbations.

fied filaments with $\mathrm{HNO}_{3}$ volume mixing ratios up to $6 \mathrm{ppbv}$ persisted until flight 21 in March 2016. While cross sections provide a qualitative insight on local nitrification patterns for selected flights, the extent of overall nitrification has been quantified based on $\mathrm{HNO}_{3}-\mathrm{O}_{3}$ correlations. Nitrification reached an extent of up to $7 \mathrm{ppbv}$ at ozone values of $1 \mathrm{ppmv}(\theta \approx 370 \mathrm{~K})$ and up to $5 \mathrm{ppbv}$ at ozone values of $0.6 \mathrm{ppmv}(\theta \approx 350 \mathrm{~K})$. A conservative correction, assuming a $15 \%$ ozone loss on the correlations would reduce these numbers to 6 and $3.5 \mathrm{ppbv}$, respectively.

The comparison of GLORIA observations with the chemistry transport model CLaMS confirms the model's ability to reproduce nitrification of the LMS. Large-scale structures are reproduced by the model that also resolves complex fine structures, although differing from measured patterns. CLaMS predominantly underestimates the enhanced values observed by GLORIA. Enhanced values are found less frequently in the simulation and are limited to narrow regions. Further, modelled $\mathrm{HNO}_{3}$ enhancements reach less far down on 12 and 20 January 2016 when compared with GLORIA. The CLaMS simulations result in a weaker nitrification of up to $4 \mathrm{ppbv}$ for the period of December to January for ozone mixing ratios between 0.8 to $1 \mathrm{ppmv}$, which is by $\sim 3$ ppbv lower than observed by GLORIA. For flight 21 in March, CLaMS underestimates the observed ozone volume mixing ratios, potentially indicating insufficient subsidence and stronger mixing in the model (Johansson et al., 2019). Sensitivity studies with CLaMS considering (i) ice formation on NAT particles, (ii) a $1 \mathrm{~K}$ global temperature offset, (iii) growth rates of aspherical particles or (iv) temperature fluctuations were performed. While the "ice formation" simulation shows only slight differences, the other cases show noticeable differences during individual flights. The temperature fluctuation simulation provides improved agreement for the flight on 31 January 2016 but also worsens the results for the flight on 20 January 2016 . The T-1K simulation improves the results for the flights 6 and 8 in January but deteriorates the results for the flight in the late winter on 18 March 2016. This shows the sensitivity of the simulation results on temperature. Potentially, a higher resolution in time and space would result in more realistic temperature fluctuations and could improve the simulations. The aspherical particle case shows slightly more pronounced improvements for the flights in mid-January. Even though the sensitivity simulations partially improve the results, distinct differences between model and measurements remain. Therefore, we conclude that a more comprehensive change in the model representations is required. However, the sensitivity simulations suggest that particle microphysics play a significant role for LMS nitrification in January. Increasing discrepancies from the observations towards the end of the winter are attributed to simulated air subsidence, transport and mixing processes.

Several studies investigated nitrification in previous cold winters, although mainly with a focus on higher altitudes. Hübler et al. (1990) interpreted enhanced $\mathrm{NO}_{y}$ values of up to $12 \mathrm{ppbv}$ at altitudes between 10 and $12.5 \mathrm{~km}$ in the Arctic winter 1988-1989 as a result of nitrification. For the Arctic winter 2002-2003 Grooß et al. (2005) modelled a nitrifica- 
tion of less than $1 \mathrm{ppbv}$ for potential temperatures lower than 360 K. For the Arctic winter 2004-2005, Dibb et al. (2006) observed nitrification of up to 3 ppbv for potential temperatures between 360 and $340 \mathrm{~K}$. Jin et al. (2006) reported an average nitrification of less than 2 ppbv for potential temperatures lower than $370 \mathrm{~K}$ for the same winter. Further, during the Arctic winter 2009-2010 (Grooß et al., 2014) modelled a nitrification of less than $1 \mathrm{ppbv}$ for potential temperatures lower than $360 \mathrm{~K}$, while (Woiwode et al., 2014) found no significant indications for nitrification below $370 \mathrm{~K}$. Since Arctic winters might show a tendency towards colder stratospheric temperatures (Rex et al., 2006), disturbances of the LMS NO$y$ budget by nitrification are likely becoming more frequent. During the Arctic winter 2015-2016 exceptionally low stratospheric temperatures occurred, and the vortex was sufficiently stable to allow formation of PSCs down to lowest stratospheric altitudes. Those conditions were the prerequisites for the strong nitrification observed and presented here. The measurements obtained by GLORIA during the POLSTRACC campaign document in detail a strong impact of nitrification on the LMS during an entire Arctic winter.
Data availability. The discussed GLORIA data set is available at the HALO database at https://halo-db.pa.op.dlr.de/ (last access: 4 November 2019) and at the KITopen repository (https: //doi.org/10.5445/IR/1000086506, Johansson et al., 2018b). NASA MERRA-2 reanalysis data are available at https://disc.gsfc.nasa. gov/ (last access: 4 November 2019). 


\section{Appendix A}

Figure A1a shows the flight track and GLORIA tangent of points of flight 5 on 21 December 2015. The flight accessed air masses associated with the sub-vortex and its vicinity in the region around Scandinavia. Figure Alb and c show the associated vertical cross sections of $\mathrm{O}_{3}$ and $\mathrm{HNO}_{3}$ derived from the GLORIA observations.
Figure A2a shows the flight track and GLORIA tangent of points of flight 6 on 12 January 2016. The flight crossed the polar front jet stream above Italy and accessed sub-vortex air masses between northern Italy and Scandinavia. The associated vertical cross sections of $\mathrm{O}_{3}$ and $\mathrm{HNO}_{3}$ derived from the GLORIA observations are shown in Fig. A2b and c. (a)

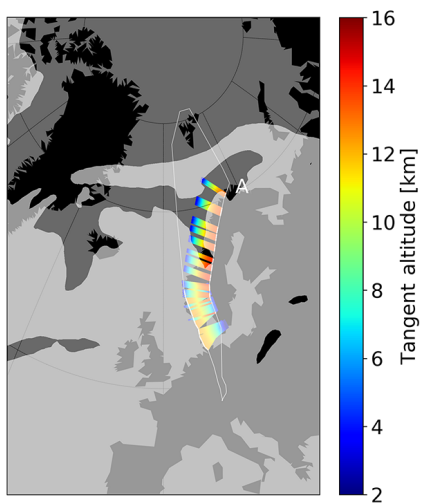

(b)

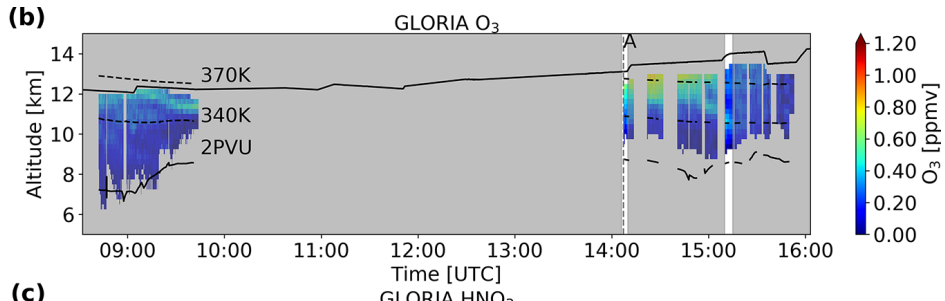

(c) GLORIA HNO

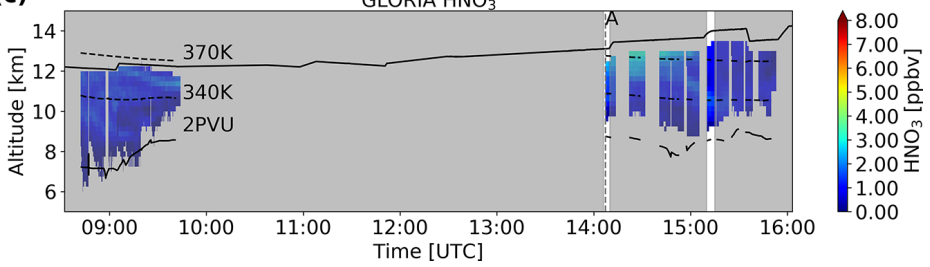

Figure A1. (a) Flight path and vortex filtering according to the Nash criterion at $370 \mathrm{~K}$ for flight 5 on 21 December 2015 . White line: flight track with characteristic waypoint (A); dark grey shading: areas that are associated with the polar vortex. Cross sections of (b) $\mathrm{O}_{3}$ and (c) $\mathrm{HNO}_{3}$ distribution derived from GLORIA. Flight altitude (bold black line), characteristic waypoint (A), 340 and $370 \mathrm{~K}$ potential temperature levels (MERRA-2, dashed black lines), and 2 PVU level (MERRA-2, black line). Passages attributed to non-sub-vortex air are shaded in grey.

(a)

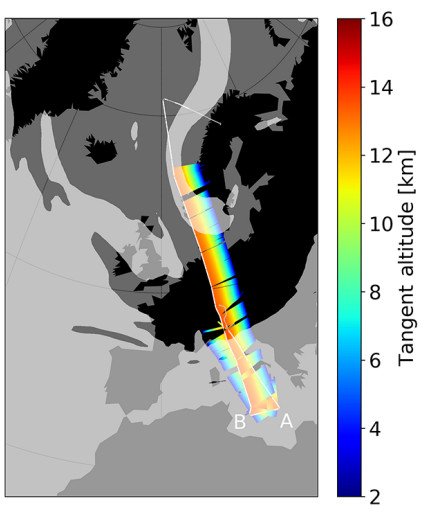

(b)

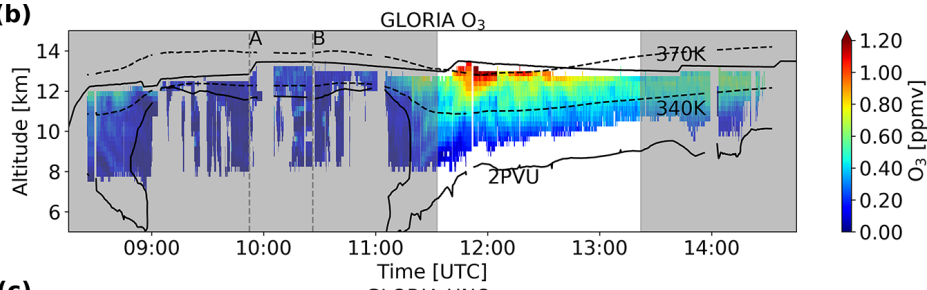

(c)

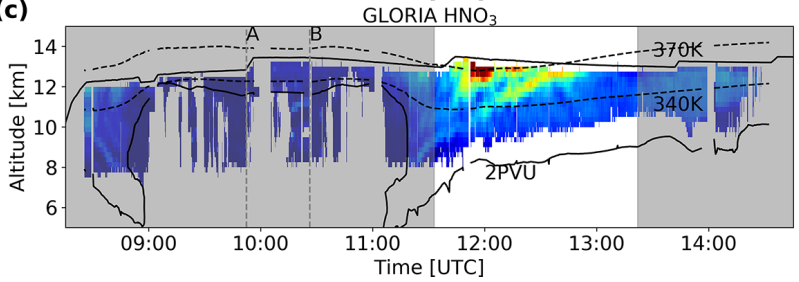

8.00 $-7.00 \div$ $5.00 \div$ 4.00 $-3.00 \stackrel{\text { O }}{2}$

2.00 工 1.00

Figure A2. (a) Flight path and vortex filtering according to the Nash criterion at $370 \mathrm{~K}$ for flight 6 on 12 January 2016 . White line: flight track with characteristic waypoint $(\mathrm{A}, \mathrm{B})$; dark grey shading: areas that are associated with the polar vortex. Cross sections of (b) $\mathrm{O}_{3}$ and (c) $\mathrm{HNO}_{3}$ distribution derived from GLORIA. Flight altitude (bold black line), characteristic waypoints (A, B), 340 and $370 \mathrm{~K}$ potential temperature levels (MERRA-2, dashed black lines), and 2 PVU level (MERRA-2, black line). Passages attributed to non-sub-vortex air are shaded in grey. 


\section{Appendix B}

(a)

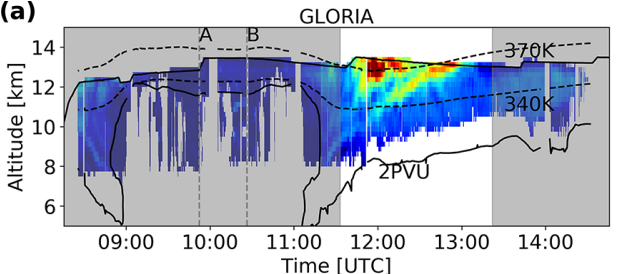

(c)

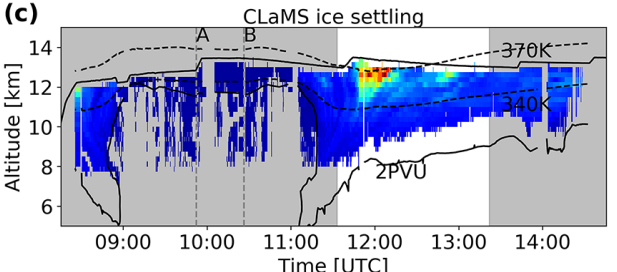

(e)

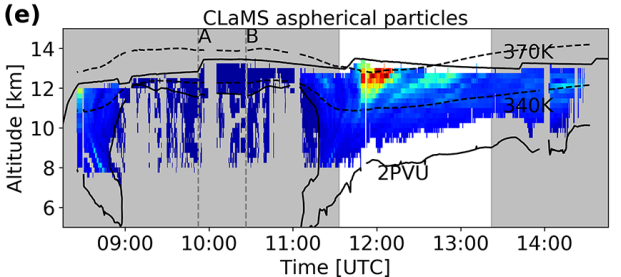

(b)
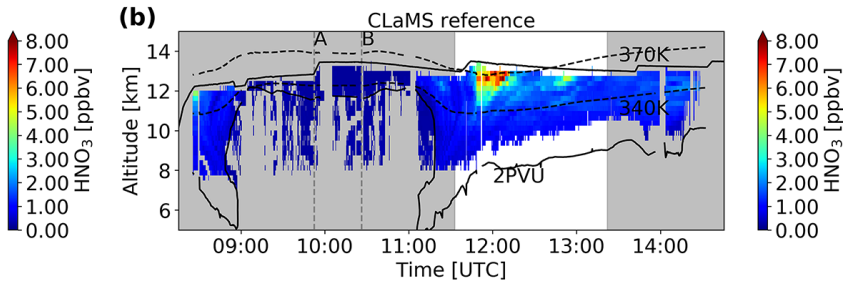

(d)

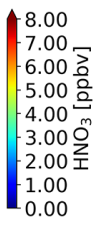

$$
\text { 政 }
$$
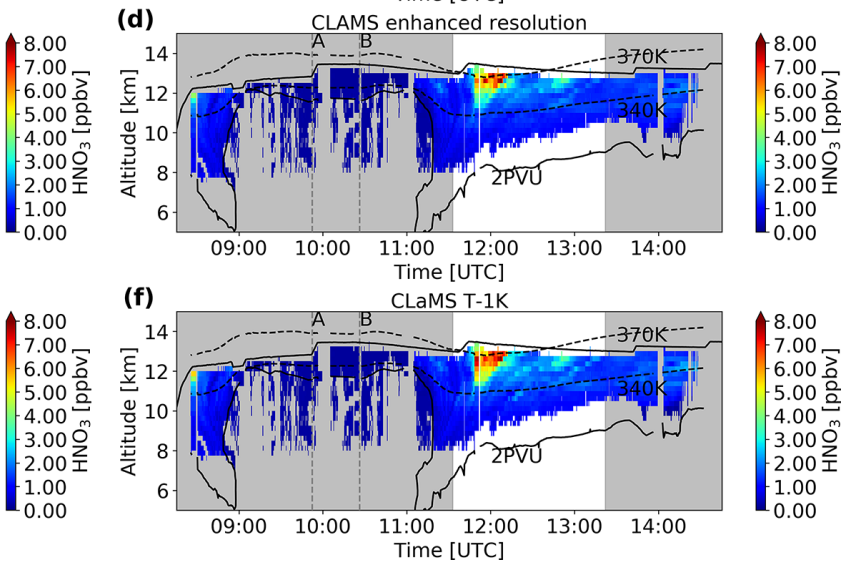

Figure B1. Cross sections of $\mathrm{HNO}_{3}$ volume mixing ratio distribution for flight 6 on 12 January 2016 derived by GLORIA (a) and modelled by the CLaMS reference simulation (b), and sensitivity simulations considering (c) ice formation on NAT particles, (d) temperature fluctuations, (e) growth rates of aspherical particles and (f) $1 \mathrm{~K}$ global temperature offset. Flight altitude (bold black line), characteristic waypoints (A, B, C), 340 and $370 \mathrm{~K}$ potential temperature levels (MERRA-2, dashed black lines), and 2 PVU level (MERRA-2, black line).

(9)

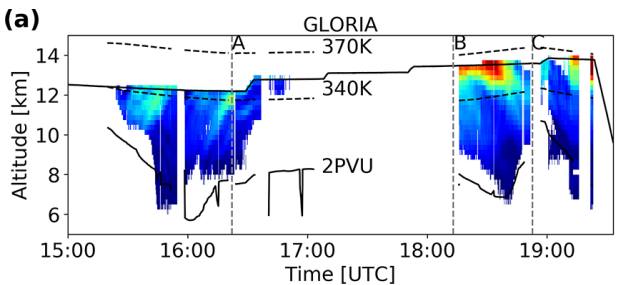

(c) CLaMS ice settling

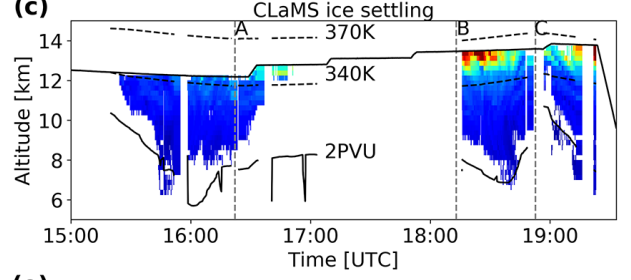

(e)

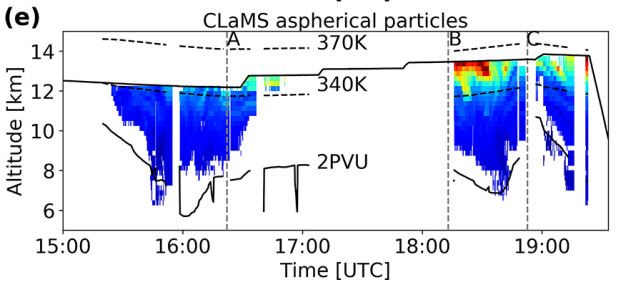

(b)

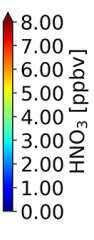

(b)

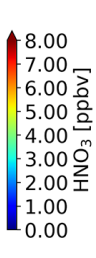

(d)

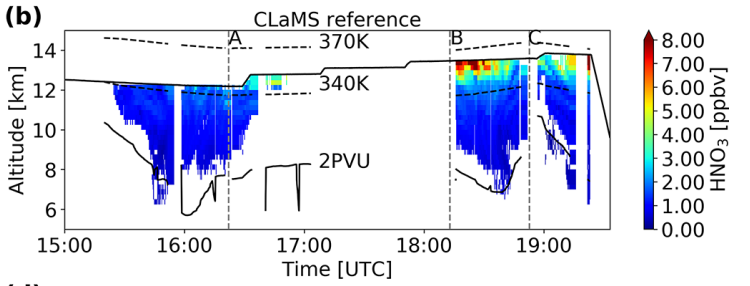
CLAMS enhanced resolution

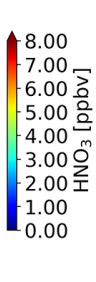

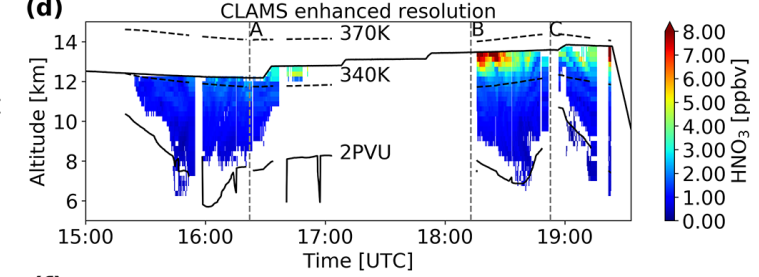

(f)

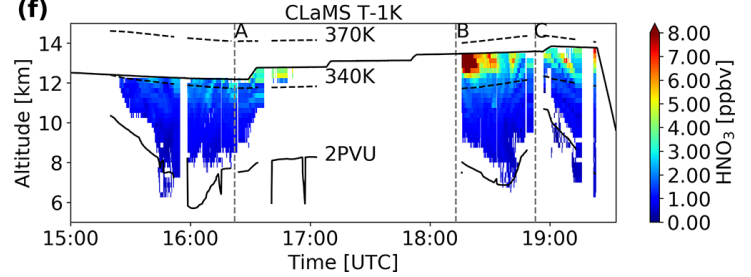

Figure B2. Cross sections of $\mathrm{HNO}_{3}$ volume mixing ratio distribution for flight 8 on 20 January 2016 derived by GLORIA (a) and modelled by the CLaMS reference simulation (b), and sensitivity simulations considering (c) ice formation on NAT particles, (d) temperature fluctuations, (e) growth rates of aspherical particles and (f) $1 \mathrm{~K}$ global temperature offset. Flight altitude (bold black line), characteristic waypoints (A, B, C), 340 and $370 \mathrm{~K}$ potential temperature levels (MERRA-2, dashed black lines), and 2 PVU level (MERRA-2, black line). 
(a)

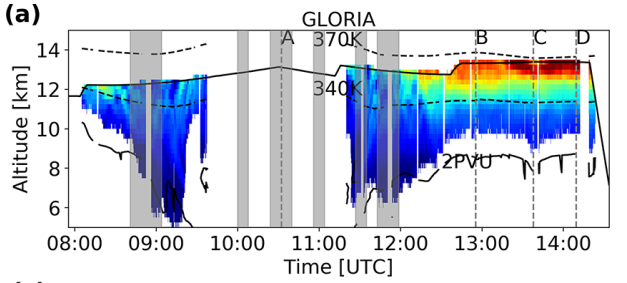

(c)

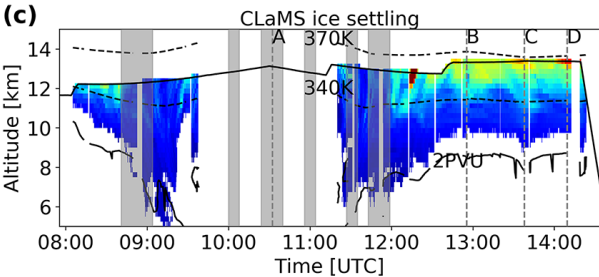

(e)

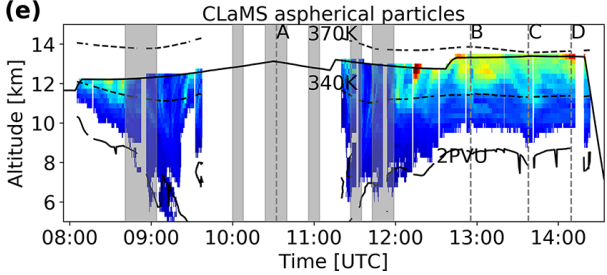

(b)
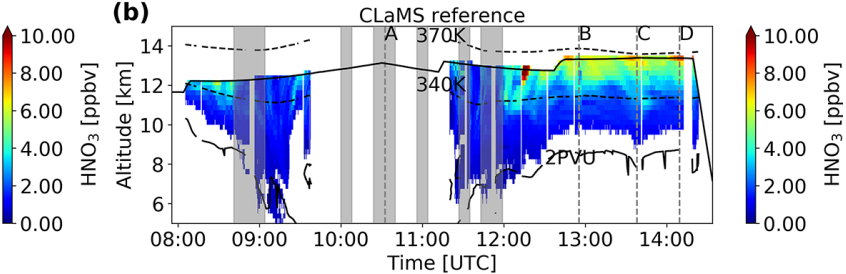

(d)
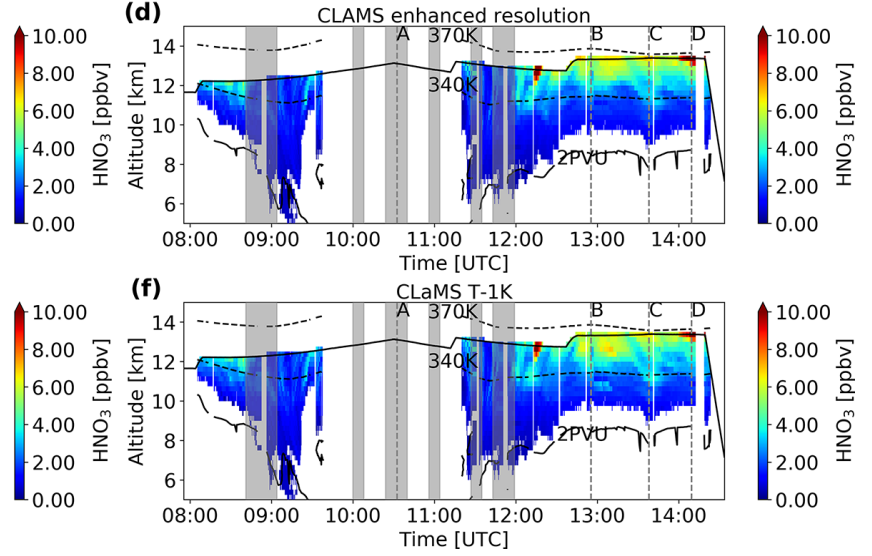

Figure B3. Cross sections of $\mathrm{HNO}_{3}$ volume mixing ratio distribution for flight 12 on 31 January 2016 derived by GLORIA (a) and modelled by the CLaMS reference simulation (b), and sensitivity simulations considering (c) ice formation on NAT particles, (d) temperature fluctuations, (e) growth rates of aspherical particles and (f) $1 \mathrm{~K}$ global temperature offset. Flight altitude (bold black line), characteristic waypoints (A, B, C, D), 340 and $370 \mathrm{~K}$ potential temperature levels (MERRA-2, dashed black lines), and 2 PVU level (MERRA-2, black line). Please note the changed colour bar compared to Figs. B1, B2, B4.

(a)

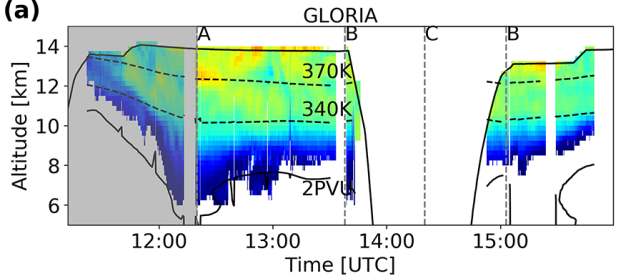

(c)

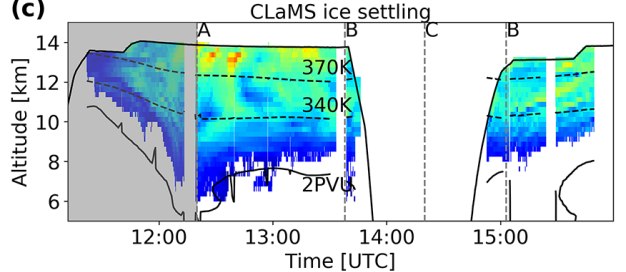

(e)

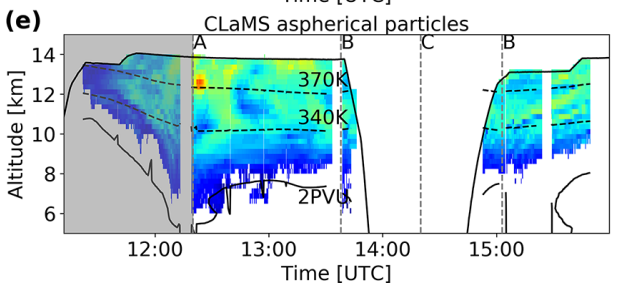

(b)
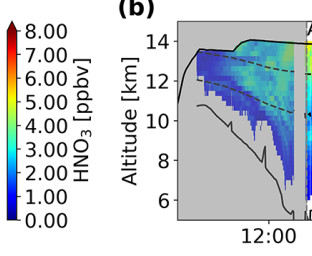

CLaMS reference
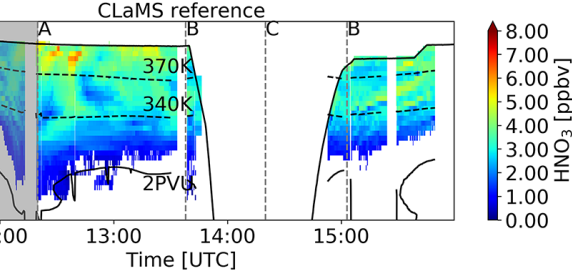

(d)

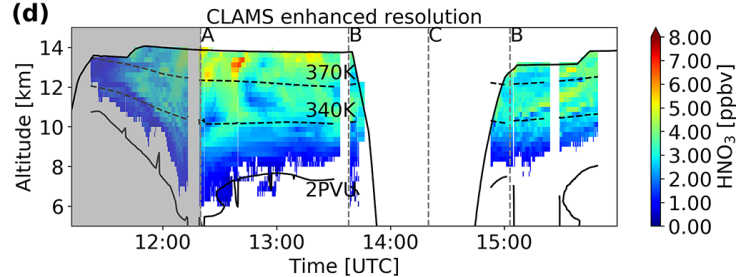

(f)

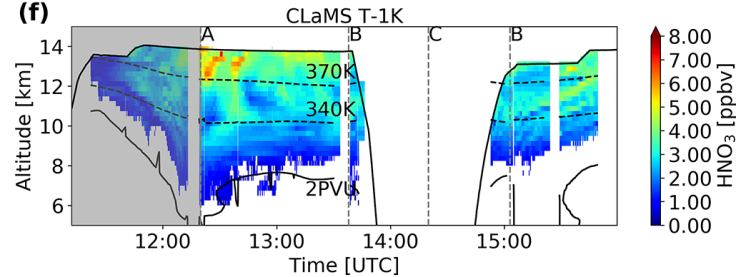

Figure B4. Cross sections of $\mathrm{HNO}_{3}$ volume mixing ratio distribution for flight 21 on 18 March 2016 derived by GLORIA (a) and modelled by the CLaMS reference simulation (b), and sensitivity simulations considering (c) ice formation on NAT particles, (d) temperature fluctuations, (e) growth rates of aspherical particles and (f) $1 \mathrm{~K}$ global temperature offset. Flight altitude (bold black line), characteristic waypoints (A, B, C), 340 and $370 \mathrm{~K}$ potential temperature levels (MERRA-2, dashed black lines), and 2 PVU level (MERRA-2, black line). 
Author contributions. MB conducted the analysis and interpretation of GLORIA level-2 data and model simulations, and prepared the paper with contributions from all co-authors. JUG performed the CLaMS model simulations. SJ, JU and WW performed the level-1 and level-2 analyses of GLORIA data. MH contributed to the GLORIA data analysis and interpretation. FFV and PP coordinated the GLORIA operations during the PGS campaign. HO and BMS coordinated the PGS field campaign. $\mathrm{HZ}$ provided the particle $\mathrm{HNO}_{3}$ data. PB contributed to the interpretation and the paper preparation.

Competing interests. The authors declare that they have no conflict of interest.

Special issue statement. This article is part of the special issue "The Polar Stratosphere in a Changing Climate (POLSTRACC) (ACP/AMT inter-journal SI)". It is not associated with a conference.

Acknowledgements. We thank the PGS coordination team and the DLR-FX for successfully conducting the field campaign. The results are based on the efforts of all members of the GLORIA team, including the technology institutes ZEA-1 and ZEA-2 at Forschungszentrum Jülich. We thank NASA for providing their MERRA-2 meteorological reanalysis data set.

Financial support. We acknowledge the computing time for the CLaMS 5 simulations granted on the supercomputer JURECA at Jülich Supercomputing Centre (JSC) under the VSR project ID JICG11. This work was supported by the German Research Foundation (Deutsche Forschungsgemeinschaft, DFG Priority Program SPP 1294). Research by Wolfgang Woiwode is supported by the DFG grant WO 2160/1-1. Sören Johansson has received funding from the European Commission's Seventh Framework Programme (FP7/2007-2013) under grant agreement 603557. Further support was received by the German research initiative ROMIC (Role of the Middle Atmosphere in Climate) and by the German Ministry of Research and Education (BMBF) project "Investigation of the life cycle of gravity waves" (GW-LCYCLE, subproject 2, 01LG1206B). We acknowledge support by the Deutsche Forschungsgemeinschaft and the Open Access Publishing Fund of the Karlsruhe Institute of Technology.

The article processing charges for this open-access publication were covered by a Research

Centre of the Helmholtz Association.

Review statement. This paper was edited by Martyn Chipperfield and reviewed by two anonymous referees.

\section{References}

Carslaw, K. S.: A vortex-scale simulation of the growth and sedimentation of large nitric acid hydrate particles, J. Geophys. Res., 107, SOL 43-1-SOL 43-16, https://doi.org/10.1029/2001JD000467, 2002.

Carslaw, K. S., Wirth, M., Tsias, A., Luo, B. P., Dörnbrack, A., Leutbecher, M., Volkert, H., Renger, W., Bacmeister, J. T., and Peter, T.: Particle microphysics and chemistry in remotely observed mountain polar stratospheric clouds, J. Geophys. Res.Atmos., 103, 5785-5796, https://doi.org/10.1029/97JD03626, 1998.

Davies, S., Mann, G. W., Carslaw, K. S., Chipperfield, M. P., Kettleborough, J. A., Santee, M. L., Oelhaf, H., Wetzel, G., Sasano, Y., and Sugita, T.: 3-D microphysical model studies of Arctic denitrification: comparison with observations, Atmos. Chem. Phys., 5, 3093-3109, https://doi.org/10.5194/acp-5-3093-2005, 2005.

Dee, D. P., Uppala, S. M., Simmons, A. J., Berrisford, P., Poli, P., Kobayashi, S., Andrae, U., Balmaseda, M. A., Balsamo, G., Bauer, P., Bechtold, P., Beljaars, A. C. M., van de Berg, L., Bidlot, J., Bormann, N., Delsol, C., Dragani, R., Fuentes, M., Geer, A. J., Haimberger, L., Healy, S. B., Hersbach, H., Hólm, E. V., Isaksen, L., Kållberg, P., Köhler, M., Matricardi, M., McNally, A. P., Monge-Sanz, B. M., Morcrette, J.-J., Park, B.-K., Peubey, C., de Rosnay, P., Tavolato, C., Thépaut, J.-N., and Vitart, F.: The ERA-Interim reanalysis: configuration and performance of the data assimilation system, Q. J. Roy. Meteor. Soc., 137, 553-597, https://doi.org/10.1002/qj.828, 2011.

Dibb, J. E., Scheuer, E., Avery, M., Plant, J., and Sachse, G.: In situ evidence for renitrification in the Arctic lower stratosphere during the polar aura validation experiment (PAVE), Geophys. Res. Lett., 33, L12815, https://doi.org/10.1029/2006GL026243, 2006.

Dunkerton, T. J. and Delisi, D. P.: Evolution of potential vorticity in the winter stratosphere of January-February 1979, J. Geophys. Res., 91, 1199, https://doi.org/10.1029/JD091iD01p01199, 1986.

Eckstein, J., Ruhnke, R., Pfahl, S., Christner, E., Diekmann, C., Dyroff, C., Reinert, D., Rieger, D., Schneider, M., Schröter, J., Zahn, A., and Braesicke, P.: From climatological to smallscale applications: simulating water isotopologues with ICONART-Iso (version 2.3), Geosci. Model Dev., 11, 5113-5133, https://doi.org/10.5194/gmd-11-5113-2018, 2018.

Engel, I., Luo, B. P., Pitts, M. C., Poole, L. R., Hoyle, C. R., Grooß, J.-U., Dörnbrack, A., and Peter, T.: Heterogeneous formation of polar stratospheric clouds - Part 2: Nucleation of ice on synoptic scales, Atmos. Chem. Phys., 13, 10769-10785, https://doi.org/10.5194/acp-13-10769-2013, 2013.

Fahey, D. W., Kelly, K. K., Ferry, G. V., Poole, L. R., Wilson, J. C., Murphy, D. M., Loewenstein, M., and Chan, K. R.: In situ measurements of total reactive nitrogen, total water, and aerosol in a polar stratospheric cloud in the Antarctic, J. Geophys. Res.-Atmos., 94, 11299-11315, https://doi.org/10.1029/JD094iD09p11299, 1989.

Fahey, D. W., Kelly, K. K., Kawa, S. R., Tuck, A. F., Loewenstein, M., Chan, K. R., and Heidt, L. E.: Observations of denitrification and dehydration in the winter polar stratospheres, Nature, 344, 321-324, https://doi.org/10.1038/344321a0, 1990.

Feigl, C., Schlager, H., Ziereis, H., Curtius, J., Arnold, F., and Schiller, C.: Observation of $\mathrm{NO}_{y}$ uptake by particles in the Arc- 
tic tropopause region at low temperatures, Geophys. Res. Lett., 26, 2215-2218, https://doi.org/10.1029/1999GL900338, 1999.

Fischer, H., Waibel, A. E., Welling, M., Wienhold, F. G., Zenker, T., Crutzen, P. J., Arnold, F., Bürger, V., Schneider, J., Bregman, A., Lelieveld, J., and Siegmund, P. C.: Observations of high concentrations of total reactive nitrogen $\left(\mathrm{NO}_{y}\right)$ and nitric acid $\left(\mathrm{HNO}_{3}\right)$ in the lower Arctic stratosphere during the StratosphereTroposphere Experiment by Aircraft Measurements (STREAM) II campaign in February 1995, J. Geophys. Res.-Atmos., 102, 23559-23571, https://doi.org/10.1029/97JD02012, 1997.

Fischer, H., Birk, M., Blom, C., Carli, B., Carlotti, M., von Clarmann, T., Delbouille, L., Dudhia, A., Ehhalt, D., Endemann, M., Flaud, J. M., Gessner, R., Kleinert, A., Koopman, R., Langen, J., López-Puertas, M., Mosner, P., Nett, H., Oelhaf, H., Perron, G., Remedios, J., Ridolfi, M., Stiller, G., and Zander, R.: MIPAS: an instrument for atmospheric and climate research, Atmos. Chem. Phys., 8, 2151-2188, https://doi.org/10.5194/acp-8-21512008, 2008.

Friedl-Vallon, F., Gulde, T., Hase, F., Kleinert, A., Kulessa, T., Maucher, G., Neubert, T., Olschewski, F., Piesch, C., Preusse, P., Rongen, H., Sartorius, C., Schneider, H., Schönfeld, A., Tan, V., Bayer, N., Blank, J., Dapp, R., Ebersoldt, A., Fischer, H., Graf, F., Guggenmoser, T., Höpfner, M., Kaufmann, M., Kretschmer, E., Latzko, T., Nordmeyer, H., Oelhaf, H., Orphal, J., Riese, M., Schardt, G., Schillings, J., Sha, M. K., Suminska-Ebersoldt, O., and Ungermann, J.: Instrument concept of the imaging Fourier transform spectrometer GLORIA, Atmos. Meas. Tech., 7, 35653577, https://doi.org/10.5194/amt-7-3565-2014, 2014.

Gelaro, R., McCarty, W., Suárez, M. J., Todling, R., Molod, A., Takacs, L., Randles, C. A., Darmenov, A., Bosilovich, M. G., Reichle, R., Wargan, K., Coy, L., Cullather, R., Draper, C., Akella, S., Buchard, V., Conaty, A., da Silva, A. M., Gu, W., Kim, G.K., Koster, R., Lucchesi, R., Merkova, D., Nielsen, J. E., Partyka, G., Pawson, S., Putman, W., Rienecker, M., Schubert, S. D., Sienkiewicz, M., and Zhao, B.: The Modern-Era Retrospective Analysis for Research and Applications, Version 2 (MERRA-2), J. Climate, 30, 5419-5454, https://doi.org/10.1175/JCLI-D-160758.1, 2017.

Gettelman, A., Hoor, P., Pan, L. L., Randel, W. J., Hegglin, M. I., and Birner, T.: THE EXTRATROPICAL UPPER TROPOSPHERE AND LOWER STRATOSPHERE, Rev. Geophys., 49, RG3003, https://doi.org/10.1029/2011RG000355, 2011.

Grooß, J.-U., Günther, G., Müller, R., Konopka, P., Bausch, S., Schlager, H., Voigt, C., Volk, C. M., and Toon, G. C.: Simulation of denitrification and ozone loss for the Arctic winter 2002/2003, Atmos. Chem. Phys., 5, 1437-1448, https://doi.org/10.5194/acp5-1437-2005, 2005.

Grooß, J.-U., Engel, I., Borrmann, S., Frey, W., Günther, G., Hoyle, C. R., Kivi, R., Luo, B. P., Molleker, S., Peter, T., Pitts, M. C., Schlager, H., Stiller, G., Vömel, H., Walker, K. A., and Müller, R.: Nitric acid trihydrate nucleation and denitrification in the Arctic stratosphere, Atmos. Chem. Phys., 14, 1055-1073, https://doi.org/10.5194/acp-14-1055-2014, 2014.

Höpfner, M., Larsen, N., Spang, R., Luo, B. P., Ma, J., Svendsen, S. H., Eckermann, S. D., Knudsen, B., Massoli, P., Cairo, F., Stiller, G., v. Clarmann, T., and Fischer, H.: MIPAS detects Antarctic stratospheric belt of NAT PSCs caused by mountain waves, Atmos. Chem. Phys., 6, 1221-1230, https://doi.org/10.5194/acp-61221-2006, 2006.
Höpfner, M., Blom, C. E., Echle, G., Glatthor, N., Hase, F., Stiller, G. P., Karlsruhe, F., and Karlsruhe, U. G.: Retrieval simulations for MIPAS-STR measurements, in: IRS 2000: Current Problems in Atmospheric Radiation, Proc. of the Internat. Radiation Symp., St.Petersburg, DEEPAK Publ., 2001.

Hoyle, C. R., Engel, I., Luo, B. P., Pitts, M. C., Poole, L. R., Grooß, J.-U., and Peter, T.: Heterogeneous formation of polar stratospheric clouds - Part 1: Nucleation of nitric acid trihydrate (NAT), Atmos. Chem. Phys., 13, 9577-9595, https://doi.org/10.5194/acp-13-9577-2013, 2013.

Hübler, G., Fahey, D. W., Kelly, K. K., Montzka, D. D., Carroll, M. A., Tuck, A. F., Heidt, L. E., Pollock, W. H., Gregory, G. L., and Vedder, J. F.: Redistribution of reactive odd nitrogen in the lower Arctic stratosphere, Geophys. Res. Lett., 17, 453-456, https://doi.org/10.1029/GL017i004p00453, 1990.

Jin, J. J., Semeniuk, K., Manney, G. L., Jonsson, A. I., Beagley, S. R., McConnell, J. C., Rinsland, C. P., Boone, C. D., Walker, K. A., and Bernath, P. F.: Denitrification in the Arctic winter 2004/2005: Observations from ACE-FTS, Geophys. Res. Lett., 33, L15S01, https://doi.org/10.1029/2006GL027687, 2006.

Johansson, S., Woiwode, W., Höpfner, M., Friedl-Vallon, F., Kleinert, A., Kretschmer, E., Latzko, T., Orphal, J., Preusse, P., Ungermann, J., Santee, M. L., Jurkat-Witschas, T., Marsing, A., Voigt, C., Giez, A., Krämer, M., Rolf, C., Zahn, A., Engel, A., Sinnhuber, B.-M., and Oelhaf, H.: Airborne limb-imaging measurements of temperature, $\mathrm{HNO}_{3}, \mathrm{O}_{3}, \mathrm{ClONO}_{2}, \mathrm{H}_{2} \mathrm{O}$ and CFC-12 during the Arctic winter 2015/2016: characterization, in situ validation and comparison to Aura/MLS, Atmos. Meas. Tech., 11, 4737-4756, https://doi.org/10.5194/amt-11-4737-2018, $2018 \mathrm{a}$.

Johansson, S., Woiwode, W., and Höpfner, M.: GLORIA Chemistry Mode temperature and trace gas retrievals from the POLSTRACC/GWLCYCLEII/GWEX/SALSA campaigns 2015/2016, KIT Bibliothek, https://doi.org/10.5445/IR/1000086506, 2018b.

Johansson, S., Santee, M. L., Grooß, J.-U., Höpfner, M., Braun, M., Friedl-Vallon, F., Khosrawi, F., Kirner, O., Kretschmer, E., Oelhaf, H., Orphal, J., Sinnhuber, B.-M., Tritscher, I., Ungermann, J., Walker, K. A., and Woiwode, W.: Unusual chlorine partitioning in the 2015/16 Arctic winter lowermost stratosphere: observations and simulations, Atmos. Chem. Phys., 19, 8311-8338, https://doi.org/10.5194/acp-19-8311-2019, 2019.

Khosrawi, F., Urban, J., Pitts, M. C., Voelger, P., Achtert, P., Kaphlanov, M., Santee, M. L., Manney, G. L., Murtagh, D., and Fricke, K.-H.: Denitrification and polar stratospheric cloud formation during the Arctic winter 2009/2010, Atmos. Chem. Phys., 11, 8471-8487, https://doi.org/10.5194/acp-118471-2011, 2011.

Khosrawi, F., Kirner, O., Sinnhuber, B.-M., Johansson, S., Höpfner, M., Santee, M. L., Froidevaux, L., Ungermann, J., Ruhnke, R., Woiwode, W., Oelhaf, H., and Braesicke, P.: Denitrification, dehydration and ozone loss during the 2015/2016 Arctic winter, Atmos. Chem. Phys., 17, 1289312910, https://doi.org/10.5194/acp-17-12893-2017, 2017.

Kim, Y., Choi, W., Lee, K., Park, J. H., Massie, S. T., Sasano, Y., Nakajima, H., and Yokota, T.: Polar stratospheric clouds observed by the ILAS-II in the Antarctic region: Dual compositions and variation of compositions during June to August of 2003, J. Geophys. Res.-Atmos., 111, D13S90, https://doi.org/10.1029/2005JD006445, 2006. 
Kleinert, A., Friedl-Vallon, F., Guggenmoser, T., Höpfner, M., Neubert, T., Ribalda, R., Sha, M. K., Ungermann, J., Blank, J., Ebersoldt, A., Kretschmer, E., Latzko, T., Oelhaf, H., Olschewski, F., and Preusse, P.: Level 0 to 1 processing of the imaging Fourier transform spectrometer GLORIA: generation of radiometrically and spectrally calibrated spectra, Atmos. Meas. Tech., 7, 41674184, https://doi.org/10.5194/amt-7-4167-2014, 2014.

Krause, J., Hoor, P., Engel, A., Plöger, F., Grooß, J.-U., Bönisch, H., Keber, T., Sinnhuber, B.-M., Woiwode, W., and Oelhaf, H.: Mixing and ageing in the polar lower stratosphere in winter 2015-2016, Atmos. Chem. Phys., 18, 6057-6073, https://doi.org/10.5194/acp-18-6057-2018, 2018.

Manney, G. L. and Lawrence, Z. D.: The major stratospheric final warming in 2016: dispersal of vortex air and termination of Arctic chemical ozone loss, Atmos. Chem. Phys., 16, 15371-15396, https://doi.org/10.5194/acp-16-15371-2016, 2016.

Manney, G. L., Zurek, R. W., O'Neill, A., and Swinbank, R.: On the Motion of Air through the Stratospheric Polar Vortex, J. Atmos. Sci., 51, 2973-2994, https://doi.org/10.1175/15200469(1994)051<2973:OTMOAT>2.0.CO;2, 1994.

Matthias, V., Dörnbrack, A., and Stober, G.: The extraordinarily strong and cold polar vortex in the early northern winter 2015/2016, Geophys. Res. Lett., 43, 12287-12294, https://doi.org/10.1002/2016GL071676, 2016.

McKenna, D. S.: A new Chemical Lagrangian Model of the Stratosphere (CLaMS) 1. Formulation of advection and mixing, J. Geophys. Res., 107, 1435, https://doi.org/10.1029/2000JD000114, 2002a.

McKenna, D. S.: A new Chemical Lagrangian Model of the Stratosphere (CLaMS) 2. Formulation of chemistry scheme and initialization, J. Geophys. Res., 107, 4256, https://doi.org/10.1029/2000JD000113, 2002b.

Molleker, S., Borrmann, S., Schlager, H., Luo, B., Frey, W., Klingebiel, M., Weigel, R., Ebert, M., Mitev, V., Matthey, R., Woiwode, W., Oelhaf, H., Dörnbrack, A., Stratmann, G., Grooß, J.U., Günther, G., Vogel, B., Müller, R., Krämer, M., Meyer, J., and Cairo, F.: Microphysical properties of synoptic-scale polar stratospheric clouds: in situ measurements of unexpectedly large $\mathrm{HNO}_{3}$-containing particles in the Arctic vortex, Atmos. Chem. Phys., 14, 10785-10801, https://doi.org/10.5194/acp-14-107852014, 2014.

Nash, E. R., Newman, P. A., Rosenfield, J. E., and Schoeberl, M. R.: An objective determination of the polar vortex using Ertel's potential vorticity, J. Geophys. Res.-Atmos., 101, 9471-9478, https://doi.org/10.1029/96JD00066, 1996.

Northway, M. J., Gao, R. S., Popp, P. J., Holecek, J. C., Fahey, D. W., Carslaw, K. S., Tolbert, M. A., Lait, L. R., Dhaniyala, S., Flagan, R. C., Wennberg, P. O., Mahoney, M. J., Herman, R. L., Toon, G. C., and Bui, T. P.: An analysis of large $\mathrm{HNO}_{3}-$ containing particles sampled in the Arctic stratosphere during the winter of 1999/2000, J. Geophys. Res.-Atmos., 107, SOL 41-1SOL 41-22, https://doi.org/10.1029/2001JD001079, 2002.

Pitts, M. C., Poole, L. R., and Gonzalez, R.: Polar stratospheric cloud climatology based on CALIPSO spaceborne lidar measurements from 2006 to 2017, Atmos. Chem. Phys., 18, 1088110913, https://doi.org/10.5194/acp-18-10881-2018, 2018.

Popp, P. J., Northway, M. J., Holecek, J. C., Gao, R. S., Fahey, D. W., Elkins, J. W., Hurst, D. F., Romashkin, P. A., Toon, G. C., Sen, B., Schauffler, S. M., Salawitch, R. J., Webster, C. R.,
Herman, R. L., Jost, H., Bui, T. P., Newman, P. A., and Lait, L. R.: Severe and extensive denitrification in the 1999-2000 Arctic winter stratosphere, Geophys. Res. Lett., 28, 2875-2878, https://doi.org/10.1029/2001GL013132, 2001.

Rex, M., Salawitch, R. J., Deckelmann, H., von der Gathen, P., Harris, N. R. P., Chipperfield, M. P., Naujokat, B., Reimer, E., Allaart, M., Andersen, S. B., Bevilacqua, R., Braathen, G. O., Claude, H., Davies, J., de Backer, H., Dier, H., Dorokhov, V., Fast, H., Gerding, M., Godin-Beekmann, S., Hoppel, K., Johnson, B., Kyrö, E., Litynska, Z., Moore, D., Nakane, H., Parrondo, M. C., Risley, A. D., Skrivankova, P., Stübi, R., Viatte, P., Yushkov, V., and Zerefos, C.: Arctic winter 2005: Implications for stratospheric ozone loss and climate change, Geophys. Res. Lett., 33, 221, https://doi.org/10.1029/2006GL026731, 2006.

Riese, M., Ploeger, F., Rap, A., Vogel, B., Konopka, P., Dameris, M., and Forster, P.: Impact of uncertainties in atmospheric mixing on simulated UTLS composition and related radiative effects, J. Geophys. Res.-Atmos., 117, D16305, https://doi.org/10.1029/2012JD017751, 2012.

Riese, M., Oelhaf, H., Preusse, P., Blank, J., Ern, M., Friedl-Vallon, F., Fischer, H., Guggenmoser, T., Höpfner, M., Hoor, P., Kaufmann, M., Orphal, J., Plöger, F., Spang, R., Suminska-Ebersoldt, O., Ungermann, J., Vogel, B., and Woiwode, W.: Gimballed Limb Observer for Radiance Imaging of the Atmosphere (GLORIA) scientific objectives, Atmos. Meas. Tech., 7, 1915-1928, https://doi.org/10.5194/amt-7-1915-2014, 2014.

Santee, M. L., Manney, G. L., Froidevaux, L., Read, W. G., and Waters, J. W.: Six years of UARS Microwave Limb Sounder HNO3 observations: Seasonal, interhemispheric, and interannual variations in the lower stratosphere, J. Geophys. Res.-Atmos., 104, 8225-8246, https://doi.org/10.1029/1998JD100089, 1999.

Sinnhuber, B.-M., Stiller, G., Ruhnke, R., von Clarmann, T., Kellmann, S., and Aschmann, J.: Arctic winter 2010/2011 at the brink of an ozone hole, Geophys. Res. Lett., 38, L24814, https://doi.org/10.1029/2011GL049784, 2011.

Stiller, G. P., von Clarmann, T., Funke, B., Glatthor, N., Hase, F., Höpfner, M., and Linden, A.: Sensitivity of trace gas abundances retrievals from infrared limb emission spectra to simplifying approximations in radiative transfer modelling, J. Quant. Spectrosc. Ra., 72, 249-280, https://doi.org/10.1016/S00224073(01)00123-6, 2002.

Stratmann, G., Ziereis, H., Stock, P., Brenninkmeijer, C., Zahn, A., Rauthe-Schöch, A., Velthoven, P., Schlager, H., and Volz-Thomas, A.: $\mathrm{NO}$ and $\mathrm{NO}_{y}$ in the upper troposphere: Nine years of CARIBIC measurements onboard a passenger aircraft, Atmos. Environ., 133, 93-111, https://doi.org/10.1016/j.atmosenv.2016.02.035, 2016.

Tabazadeh, A. and Toon, O. B.: The presence of metastable $\mathrm{HNO}_{3} / \mathrm{H}_{2} \mathrm{O}$ solid phases in the stratosphere inferred from ER 2 data, J. Geophys. Res.-Atmos., 101, 9071-9078, https://doi.org/10.1029/96JD00062, 1996.

Tritscher, I., Grooß, J.-U., Spang, R., Pitts, M. C., Poole, L. R., Müller, R., and Riese, M.: Lagrangian simulation of ice particles and resulting dehydration in the polar winter stratosphere, Atmos. Chem. Phys., 19, 543-563, https://doi.org/10.5194/acp19-543-2019, 2019.

Tuck, A. F., Baumgardner, D., Chan, K. R., Dye, J. E., Elkins, J. W., Hovde, S. J., Kelly, K. K., Loewenstein, M., Margitan, J. J., May, R. D., Podolske, J. R., Proffitt, M. H., Rosenlof, 
K. H., Smith, W. L., Webster, C. R., and Wilson, J. C.: The Brewer-Dobson Circulation In the Light of High Altitude In Situ Aircraft Observations, Q. J. Roy. Meteor. Soc., 123, 1-69, https://doi.org/10.1002/qj.49712353702, 1997.

Voigt, C., Dörnbrack, A., Wirth, M., Groß, S. M., Pitts, M. C., Poole, L. R., Baumann, R., Ehard, B., Sinnhuber, B.M., Woiwode, W., and Oelhaf, H.: Widespread polar stratospheric ice clouds in the 2015-2016 Arctic winter - implications for ice nucleation, Atmos. Chem. Phys., 18, 15623-15641, https://doi.org/10.5194/acp-18-15623-2018, 2018.

Waibel, A. E.: Arctic Ozone Loss Due to Denitrification, Science, 283, 2064-2069, https://doi.org/10.1126/science.283.5410.2064, 1999.

Waters, J. W., Froidevaux, L., Harwood, R. S., Jarnot, R. F., Pickett, H. M., Read, W. G., Siegel, P. H., Cofield, R. E., Filipiak, M. J., Flower, D. A., Holden, J. R., Lau, G. K., Livesey, N. J., Manney, G. L., Pumphrey, H. C., Santee, M. L., Wu, D. L., Cuddy, D. T., Lay, R. R., Loo, M. S., Perun, V. S., Schwartz, M. J., Stek, P. C., Thurstans, R. P., Boyles, M. A., Chandra, K. M., Chavez, M. C., Chen, G.-S., Chudasama, B. V., Dodge, R., Fuller, R. A., Girard, M. A., Jiang, J. H., Jiang, Y., Knosp, B. W., LaBelle, R. C., Lam, J. C., Lee, K. A., Miller, D., Oswald, J. E., Patel, N. C., Pukala, D. M., Quintero, O., Scaff, D. M., van Snyder, W., Tope, M. C., Wagner, P. A., and Walch, M. J.: The Earth observing system microwave limb sounder (EOS MLS) on the aura Satellite, IEEE T. Geosci. Remote Sens., 44, 1075-1092, https://doi.org/10.1109/TGRS.2006.873771, 2006.

Werner, A., Volk, C. M., Ivanova, E. V., Wetter, T., Schiller, C., Schlager, H., and Konopka, P.: Quantifying transport into the Arctic lowermost stratosphere, Atmos. Chem. Phys., 10, 1162311639, https://doi.org/10.5194/acp-10-11623-2010, 2010.
Woiwode, W., Grooß, J.-U., Oelhaf, H., Molleker, S., Borrmann, S., Ebersoldt, A., Frey, W., Gulde, T., Khaykin, S., Maucher, G., Piesch, C., and Orphal, J.: Denitrification by large NAT particles: the impact of reduced settling velocities and hints on particle characteristics, Atmos. Chem. Phys., 14, 11525-11544, https://doi.org/10.5194/acp-14-11525-2014, 2014.

Woiwode, W., Höpfner, M., Bi, L., Pitts, M. C., Poole, L. R., Oelhaf, H., Molleker, S., Borrmann, S., Klingebiel, M., Belyaev, G., Ebersoldt, A., Griessbach, S., Grooß, J.-U., Gulde, T., Krämer, M., Maucher, G., Piesch, C., Rolf, C., Sartorius, C., Spang, R., and Orphal, J.: Spectroscopic evidence of large aspherical $\beta$-NAT particles involved in denitrification in the December 2011 Arctic stratosphere, Atmos. Chem. Phys., 16, 9505-9532, https://doi.org/10.5194/acp-16-9505-2016, 2016.

Zhu, Y., Toon, O. B., Pitts, M. C., Lambert, A., Bardeen, C., and Kinnison, D. E.: Comparing simulated PSC optical properties with CALIPSO observations during the 2010 Antarctic winter, J. Geophys. Res.-Atmos., 122, 1175-1202, https://doi.org/10.1002/2016JD025191, 2017.

Ziereis, H., Minikin, A., Schlager, H., Gayet, J. F., Auriol, F., Stock, P., Baehr, J., Petzold, A., Schumann, U., Weinheimer, A., Ridley, B., and Ström, J.: Uptake of reactive nitrogen on cirrus cloud particles during INCA, Geophys. Res. Lett., 31, L05115, https://doi.org/10.1029/2003GL018794, 2004. 